\title{
Microstructure and Oxidation Performance of TiAl-(Cr, Nb, Ta) Coatings Fabricated by Warm Spray and High-Velocity Oxy-Fuel Spraying
}

\author{
Judyta Sienkiewicz $^{1}\left(D_{0} \cdot\right.$ Seiji Kuroda $^{2} \cdot$ Hideyuki Murakami $^{2} \cdot$ Hiroshi Araki $^{2} \cdot$ \\ Maciej Giżyński ${ }^{3} \cdot$ Krzysztof J. Kurzydłowski $^{4}$
}

Submitted: 24 August 2018/in revised form: 23 December 2018/Published online: 6 February 2019

(C) The Author(s) 2019

\begin{abstract}
To improve the oxidation resistance of near $\alpha$ titanium alloy IMI834, TiAl-(Cr, Nb, Ta) coatings were deposited by applying high-velocity oxy-fuel (HVOF) and warm spray (WS). Comparison was made in terms of microstructure, surface morphology as well as isothermal and cyclic oxidation behaviors in the air at $750{ }^{\circ} \mathrm{C}$ up to $100 \mathrm{~h}$ and 100 cycles, respectively. The results show that smoother and less oxidized coatings were deposited by warm spraying. The microstructure of all coatings underwent an appreciable change during the oxidation tests, as in as-sprayed state it occurred in the nonequilibrium state. It was revealed that a small difference in the initial oxidation between the two spraying processes as well as microstructure, the level of porosity and surface roughness significantly influences the oxidation kinetics of the sprayed coatings at high temperature, which should affect the service lifetime as an oxidation-resistant layer for potential applications. After exposure at $750{ }^{\circ} \mathrm{C}$ in air, rutile $\mathrm{TiO}_{2}$ was found in addition to $\alpha-\mathrm{Al}_{2} \mathrm{O}_{3}$ in the oxide scale formed on the HVOF and warm sprayed coatings. However, isothermal and cyclic oxidation tests of all WS
\end{abstract}

Judyta Sienkiewicz

judyta.sienkiewicz@wat.edu.pl

1 Institute of Armament Technology, Faculty of Mechatronics and Aerospace, Military University of Technology,

Urbanowicza 2, 00-908 Warsaw, Poland

2 Research Center for Structural Materials, National Institute for Materials Science, 1-2-1, Sengen, Tsukuba-Shi, Ibaraki-ken 305-0047, Japan

3 Faculty of Materials Science and Engineering, Materials Design Division, Warsaw University of Technology, Woloska 141, 02-507 Warsaw, Poland

4 Faculty of Mechanical Engineering, Bialystok University of Technology, 45A, Wiejska Street, 15-351 Bialystok, Poland
TiAl-(Cr, Nb, Ta) coatings showed improved oxidation resistance of IMI 834 as well as good adherence to the substrate alloy.

Keywords coatings for engine components $\cdot$ hightemperature oxidation $\cdot$ interlayers $\cdot$ spray forming

\section{Introduction}

Needs for enhancements of turbine engines power, efficiency and weight reduction have stimulated the development of temperature- and creep-resistant materials with reduced density (Ref 1-4). Such requirements have driven the development of a wide range of titanium alloys culminating more recently IMI 834 alloy (Ti-5.8Al-4Sn$3.5 \mathrm{Zr}-0.7 \mathrm{Nb}-0.5 \mathrm{Mo}-0.35 \mathrm{Si}$ ), which is one of the most developed titanium alloys, operating industrially today as compressor disks and blades of advanced gas turbine engines for lightweight aircrafts (Ref 5,6).

The main constraint of using titanium at high temperature, however, is its ease of oxygen absorption leading to oxidation and alpha-case formation in the air $(\operatorname{Ref} 7,8)$. To be utilized more effectively at higher temperatures and replace heavy nickel in the compressor or even turbine section of an aircraft engine, the ingress of oxygen must be prevented by applying some protective coating systems (Ref 7, 9-11).

Titanium aluminides based on $\gamma$-TiAl phase are considered for high-temperature applications especially as thermal barrier protections for titanium alloys (Ref 12, 13). The properties of the titanium aluminides that make them attractive as a coating include outstanding oxidation resistance, low density and microstructural stability at elevated temperatures derived from their intermetallic 
nature (Ref 14-24). Also, the coefficient of expansion provides a good match with most titanium alloys. Moreover, it should be emphasized that the low density of such coating alloys provides coverage per unit mass twice as large as most other competing coating alloys such as MCrAlY ( $M$ refers to one or more of the elements $\mathrm{Co}, \mathrm{Ni}$, and $\mathrm{Fe}$ ). Besides, additional elements can further improve high-temperature oxidation resistance and modify the mechanical properties of a binary $\gamma$-TiAl compound. One of the most important of such elements is chromium that causes the development of the Laves phase that is capable of continuous $\mathrm{Al}_{2} \mathrm{O}_{3}$ scale formation (Ref 25). Niobium is another element that promotes alumina formation, mainly by changing the structure of oxides (Ref 26) or by decreasing the solubility of oxygen in the alloy (Ref 27), and hence increases oxidation resistance. It is worth to note that the addition of refractory metals as tantalum to niobium-containing compounds reduces the oxidation rate even more.

Among many coating processes, thermal spraying is attractive because of high deposition rates and ease to apply on large components and therefore is widely used for coating parts in aircraft engines. Nowadays, atmospheric plasma spraying (APS), low-pressure plasma spraying (LPPS), high-velocity oxy-fuel spraying (HVOF) and cold gas dynamic spraying (CGDS) are available for deposition of metallic and nonmetallic coatings (Ref 28). Coatings obtained by APS process usually suffer from excessive oxidation and loss of volatile elements since it is conducted under an air atmosphere, and its heat source is a plasma jet with temperature over $10,000{ }^{\circ} \mathrm{C}$. By using controlled vacuum for LPPS process, oxidation is effectively suppressed, and highly dense coatings can be obtained. However, elements with high vapor pressure tend to be lost and often coatings exhibit nonequilibrium microstructure due to rapid quenching. Recently, as an alternative to LPPS, HVOF is getting much attention where sprayed particles are usually impacted to a substrate under a semimolten condition under air atmosphere using a combustion flame jet as its heat source with a temperature below $3000{ }^{\circ} \mathrm{C}$. CGDS process deposits materials in the solid state by the use of a supersonic jet generated by expansion of highly pressured and slightly heated inert gas like nitrogen or helium through a de Laval nozzle. In CGDS, oxidation is essentially eliminated; however, it is not always possible to produce fully dense coatings since sprayed particles do not always possess sufficient deformability.

One of the newest techniques is warm spray (WS), a modification of HVOF, in which the temperature of particles can be effectively controlled to assure sufficient deformability so that they can be deposited in both the solid or semi-melting state. In WS, nitrogen gas is mixed with a supersonic combustion gas jet and hence the temperature of the propellant gas can be decreased so that the temperature of the sprayed particle can be kept under its melting point.

As mentioned before, coatings prepared by each thermal spraying technology have different characteristics including oxygen content, surface roughness, porosity and even microstructure. Further, the oxidation resistance of coatings is dominated by the nature of a thermally grown oxide (TGO), which is heavily dependent on the microstructure of the coatings.

In the past, research efforts have been focused on the deposition of TiAl coatings by using PS and HVOF (Ref 29-34). Khor et al. revealed that coatings produced by APS from TiAl intermetallic powder with the particle size of $\sim 250 \mu \mathrm{m}$ followed by hot isostatic pressing contained unmelted or partially melted particles as well as high porosity and poor adhesion (Ref 32 ). Lee et al. also observed high porosity level, which might have arisen due to incomplete melting and low deformability of particles in coatings fabricated by PS using intermetallic powder with the composition of Al-21Ti-23Cr (at.\%) (Ref 30). In terms of oxidation resistance, not much attention has been paid to explore TiAl-based intermetallics as protective coatings for titanium alloys at high temperatures due to the problems in producing continuous coatings without defects such as porosity and cracks. Nevertheless, Dewald et al. made TiAl coatings by APS, VPS and HVOF in order to investigate the thermal cyclic life of these coating at 700 and $900{ }^{\circ} \mathrm{C}$, the behavior of TGO growth and crack propagation. Their results indicated good resistance for the cyclic oxidation of HVOF and APS $(<1 \%$ oxide) deposits, whereas VPS coatings failed owing to thermal expansion differences, interface structure and residual stress state, which induced cracking in the coatings on Ti and TiAl substrates (Ref 31).

In this study, WS was applied to deposit TiAl-(Cr, $\mathrm{Nb}$, Ta) coatings to mitigate oxidation at high temperature. The reason for selecting WS was the observation that properties of TiAl intermetallic phases are expected to depend on the degree of oxidation and other microstructural and structural features as described (Ref 35,36$)$. In this context, it should be noted that WS should be able to produce less oxidized coatings as compared to HVOF. WS is also economically advantageous as it is carried out in an open air (e.g., LPPS needs a large vacuum chamber, which inevitably makes the equipment cost high) and does not require expensive propellant gas such as He to produce dense coatings. In our previous study, pre-alloyed TiAl-based powders were tested as a feedstock material for thermal spraying of protective coatings for high-temperature titanium alloys (Ref 37). A full production route of powders as well as coating's microstructure and mechanical properties have been investigated. One of the main findings was that the coating's initial microstructure evolves during annealing 
toward the equilibrium phase diagram as powder feedstock was in a nonequilibrium state. However, the transformation does not cause any undesirable effects, e.g., cracking or delamination (Ref 37). Since materials in a jet engine are exposed to repetitive heating-cooling cycles, the key feature of such protective coatings is resistant to cyclic oxidation. The protection against oxidation during thermal cycles requires good oxidation resistance itself and ability to withstand cyclic thermo-mechanical loads what is coupled with certain plasticity and crack resistance. In connection with the above, the aim of the research efforts was to develop a high-performance oxidation-resistant coating for near-alpha titanium alloy, e.g., IMI 834, to increase its operating temperature. To this end, performance of titanium alloy samples with coatings of $\mathrm{TiAl}-(\mathrm{Cr}, \mathrm{Nb}, \mathrm{Ta})$ prepared by HVOF and WS were evaluated in isothermal and cyclic oxidation tests at $750{ }^{\circ} \mathrm{C}$ in air. The relationship between the spray processes and coatings characteristics will be discussed in context to their surface roughness, oxygen concentration and microstructure.

\section{Experimental Procedure}

\section{Materials and Sample Preparation}

Ingots of three TiAl-based alloys were produced in National Institute for Materials Science (NIMS) by melting elements in $\mathrm{Y}_{2} \mathrm{O}_{3}$ crucibles in $\mathrm{Ar}$ atmosphere by using a high-frequency induction coil. The melted alloys were cast in a water-cooled mold. The chemical compositions of the ingots, obtained by the ICP method, are given in Table 1. The oxygen concentration was 0.002 (wt.\%) for TiAl and TiAl-Cr while for TiAl-Nb-Ta was 0.008 (wt.\%) and is likely to come from the $\mathrm{Y}_{2} \mathrm{O}_{3}$ crucibles. The ingots were powderized by gas atomization process performed by OSAKA Yakin Kogyo Co., Ltd. The obtained powders were characterized by scanning electron microscopy (SEM), as well as by $\mathrm{X}$-ray diffraction techniques (XRD) and ICP analysis.

Disks of $25 \mathrm{~mm}$ diameter and $2 \mathrm{~mm}$ thickness of IMI 834 were used as substrate [Nominal composition of IMI 834 is Ti-5.8Al-4Sn-3.5Zr-0.7Nb-0.5Mo-0.35Si in wt.\% (Ref 38)]. Grit blasting and degreasing were conducted just before spray deposition. Alumina grit size was around
425-500 $\mu \mathrm{m}$, blasting pressure was $0.5 \mathrm{MPa}$ and the time of ultrasonic degreasing in acetone was $10 \mathrm{~min}$.

Warm spray and high-velocity oxy-fuel were used for deposition of coatings under the conditions described in Table 2. A commercially available HVOF apparatus (Praxair, JP5000) powered by combustion of kerosene/ oxygen mixture was employed with conditions selected based on our previous publications (Ref 39-42). WS conditions have been controlled by varying the nitrogen flow rate. The best deposition efficiency (D.E.) was achieved for a nitrogen flow rate of $300 \mathrm{~L} \mathrm{~min}^{-1}$ as the optimum for the powders. D.E. was calculated by the ratio of the measured weight of the coatings to the calculated weight of the sprayed powder on the substrate. Substrates were preheated to a temperature of $200{ }^{\circ} \mathrm{C}$ before spray deposition, and they were coated on both sides.

\section{Isothermal and Cyclic Oxidation Test}

Isothermal for $100 \mathrm{~h}$ and cyclic oxidation up to 100 cycles were carried out at $750{ }^{\circ} \mathrm{C}$ using an electric furnace. One thermal cycle consisted of heating for $1 \mathrm{~h}$ at $750{ }^{\circ} \mathrm{C}$ and cooling to an ambient temperature for $40 \mathrm{~min}$ in an air atmosphere. Each specimen was placed in a crucible. All crucibles were placed on a platform, around which an electrical furnace repeated the horizontal motion, i.e., after $1 \mathrm{~h}$ heating in the furnace; it slides out on a rail to expose the samples to the ambient air. Before and after each test, the weights of the crucibles with specimens as well as bare samples and crucibles were measured to calculate the mass gain by the formation of oxides. The surface of oxidized samples was protected by Ni-plating to prevent damage on the formed oxide scale during sample's cutting and polishing.

\section{Characterization of Powders and Coatings}

The surface roughness $R_{a}$ of coatings was evaluated by a surface profilometer (Mitutoyo Corporation, Surftest SJ201). The oxygen content of powders and as-deposited coatings was analyzed by the inert gas fusion method (HORIBA, EMGA-620 W). Samples were sectioned, mounted in epoxy resin and metallographically polished before the cross-sectional observation. SEM (JEOL, JSM6010) observation with an acceleration voltage at $20 \mathrm{kV}$ was conducted for microstructure analysis. Coatings
Table 1 Chemical composition of Ti-Al-(Cr, Nb, Ta) ingots after casting

\begin{tabular}{lcccccc}
\hline & Ti, at.\% & Al, at.\% & Cr, at.\% & Nb, at.\% & Ta, at.\% & Y, at.\% \\
\hline Ti-Al & 49.17 & 50.60 & $\ldots$ & $\ldots$ & $\ldots$ & 0.23 \\
Ti-Al-Cr & 36.84 & 51.14 & 11.96 & $\ldots$ & $\ldots$ & 0.05 \\
Ti-Al-Nb-Ta & 44.63 & 46.04 & $\ldots$ & 8.25 & 0.94 & 0.14 \\
\hline
\end{tabular}


thickness and porosity as well as the thickness of scales after oxidation tests were evaluated by image analysis (Image J, National Institutes of Health) using SEM crosssectional images. For the measurement of porosity and oxides, ten images were captured in the back-scattered electron mode from each sample at 1000 magnification and analyzed to calculate the average value. Crystal structures were analyzed by XRD (Rigaku, RINT2500) using the $\mathrm{Cu}$ $\mathrm{K} \alpha$ radiation for an angle range $(2 \theta)$ of $20^{\circ}-80^{\circ}$ with a step of 0.02 and scan speed of $2^{\circ}$ per minute.

\section{Results and Discussion}

\section{Characterization of Powders}

SEM images of the gas-atomized TiAl-(Cr, $\mathrm{Nb}, \mathrm{Ta})$ alloys with powder size below $<45 \mu \mathrm{m}$ are shown in Fig. 1(a), (b) and (c). These images show that most of the particles, regardless of their size, are spherical in shape. The chemical composition of TiAl-(Cr, Nb, Ta) alloys after the gas atomization process is given in Table 3. As can be seen, oxygen content increased after the gas atomization process but still is below 0.5 at.\%. The content of other elements remained almost the same as compared to ingots given in Table 1.

Table 2 Warm spray and high-velocity oxy-fuel conditions

\begin{tabular}{lll}
\hline & \multicolumn{1}{c}{ WS } & \multicolumn{1}{c}{ HVOF } \\
\hline Kerosene flow rate & $0.407 \mathrm{~L} \mathrm{~min}^{-1}$ & $0.322 \mathrm{~L} \mathrm{~min}^{-1}$ \\
Oxygen flow rate & $840 \mathrm{~L} \mathrm{~min}^{-1}$ & $897 \mathrm{~L} \mathrm{~min}^{-1}$ \\
Nitrogen flow rate & $300 \mathrm{~L} \mathrm{~min}^{-1}$ & $\ldots$ \\
Barrel length & $400 \mathrm{~mm}$ & $200 \mathrm{~mm}$ \\
Spray distance & $200 \mathrm{~mm}$ & $350 \mathrm{~mm}$ \\
Spray gun traversing velocity & $700 \mathrm{~mm} \mathrm{~s}$ & $700 \mathrm{~mm} \mathrm{~s}$ \\
Traverse pitch & $4 \mathrm{~mm}$ & $4 \mathrm{~mm}$ \\
Number of passes & 20 & 10 \\
\hline
\end{tabular}

The cross-sectional microstructure of the powder particles and XRD patterns for powder particles are shown in Fig. 2(a), (b) and (c) together with the XRD patterns for ingots. It can be clearly seen that the TiAl powder is composed of $\alpha_{2}-\mathrm{Ti}_{3} \mathrm{Al}$ phase and $\gamma$-TiAl phase, while the ingot was composed mostly of $\gamma$-TiAl phase (Fig. 2a). For the rapidly solidified particles, the intensity of $\alpha_{2}$-phase peaks was much higher, which means that the volume fraction of the $\alpha_{2}-\mathrm{Ti}_{3} \mathrm{Al}$ phase increases also in comparison with the initial ingot. The peaks of the $\alpha_{2}$-phase contained in the powder shifted to higher angles as compared to the standard peaks for this phase, indicating that the lattice parameter decreased during rapid solidification. As a result of rapid quenching, gas-atomized powder consists of the disordered supersaturated in $\mathrm{Al}$ phases, which are expected to solidify from the liquid at first.

The dendritic microstructure of TiAl-Cr powder with brightly contrasted ribs inside the gray matrix is shown in Fig. 2(b). The higher concentration of $\mathrm{Cr}$ and $\mathrm{Ti}$ in the dendrite cores (light network) and adjacent interdendritic Al-enriched regions (gray matrix) were observed. The clearly imaged ribs formed due to the segregation of $\mathrm{Cr}$ which can be attributed to the $\beta$-phase, whereas gray intercellular region corresponds to the $\alpha$-phase, see Fig. 2 . The microstructure of TiAl-Cr powders differs from the microstructure of the ingot which consists of $\gamma$-TiAl matrix with some content of the Laves phase- $\mathrm{Ti}(\mathrm{Al}, \mathrm{Cr})_{2}$ (Ref 43)—with lattice parameters of $a=5.055 \AA$ and $c=8.265 \AA$.

Figure 2(c) shows a BSE micrograph of the microstructure of powder particles of TiAl-Nb-Ta alloy. One of the major features of the microstructure after gas atomization process is brightly contrasted network enriched in $\mathrm{Nb}$ and $\mathrm{Ta}$ (Fig. 2c) as it is well known that $\mathrm{Nb}$ is a $\beta$-phase stabilizer. Thus, the slightly light-colored network can be attributed to the $\beta$-phase. In contrast, there is a black region, in the BSE image of the gas-atomized alloy, rich in $\mathrm{Al}$ and poor in $\mathrm{Nb}$ and $\mathrm{Ta}$. Furthermore, the $\mathrm{X}$-ray phase
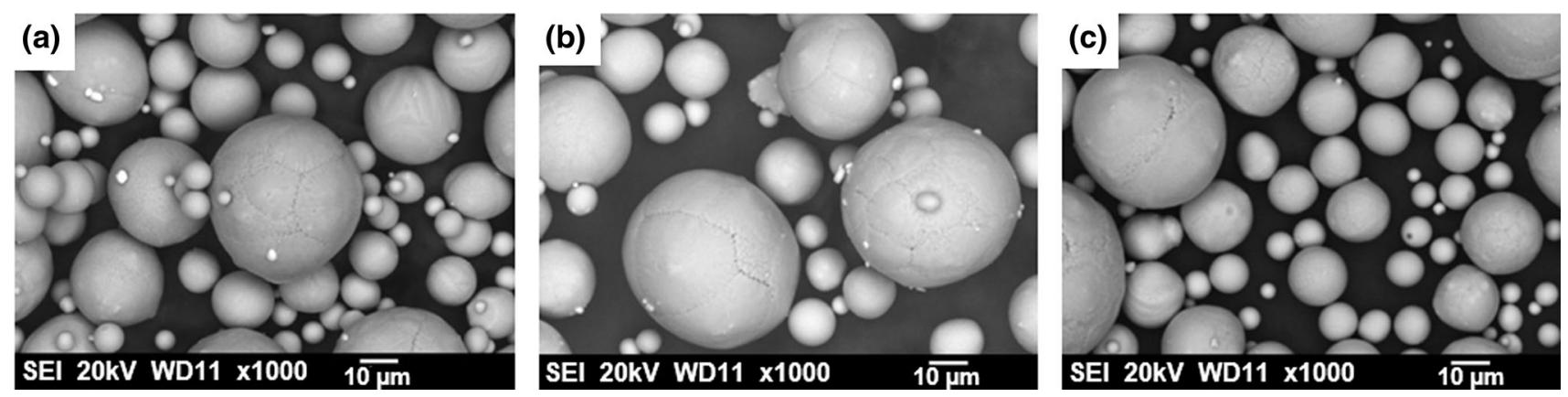

Fig. 1 SEM (secondary electron) images of powders obtained by gas atomization process made of (a) Ti-50Al, (b) Ti-51 Al-12Cr and (c) Ti$46 \mathrm{Al}-8.5 \mathrm{Nb}-1 \mathrm{Ta}$ 
Table 3 Chemical composition of powders after gas

atomization process by inert gas fusion

Fig. 2 XRD patterns and SEM cross sections of (a) Ti-50Al,

(b) Ti-51Al-12Cr, (c) Ti-46Al-

$8.5 \mathrm{Nb}-1 \mathrm{Ta}$ powders

\begin{tabular}{lcccccccc}
\hline & Ti, at.\% & $\mathrm{Al}$, at.\% & $\mathrm{Cr}$, at. $\%$ & $\mathrm{Nb}$, at.\% & $\mathrm{Ta}$, at.\% & $\mathrm{Y}$, at.\% & $\mathrm{O}$, at.\% & $\mathrm{N}$, at.\% \\
\hline Ti-Al & 49.19 & 50.09 & $\ldots$ & $\ldots$ & $\ldots$ & 0.22 & 0.47 & 0.010 \\
Ti-Al-Cr & 37.62 & 50.19 & 11.93 & $\ldots$ & $\ldots$ & 0.04 & 0.20 & 0.020 \\
Ti-Al-Nb-Ta & 43.93 & 46.23 & $\ldots$ & 8.32 & 0.96 & 0.14 & 0.35 & 0.007 \\
\hline
\end{tabular}
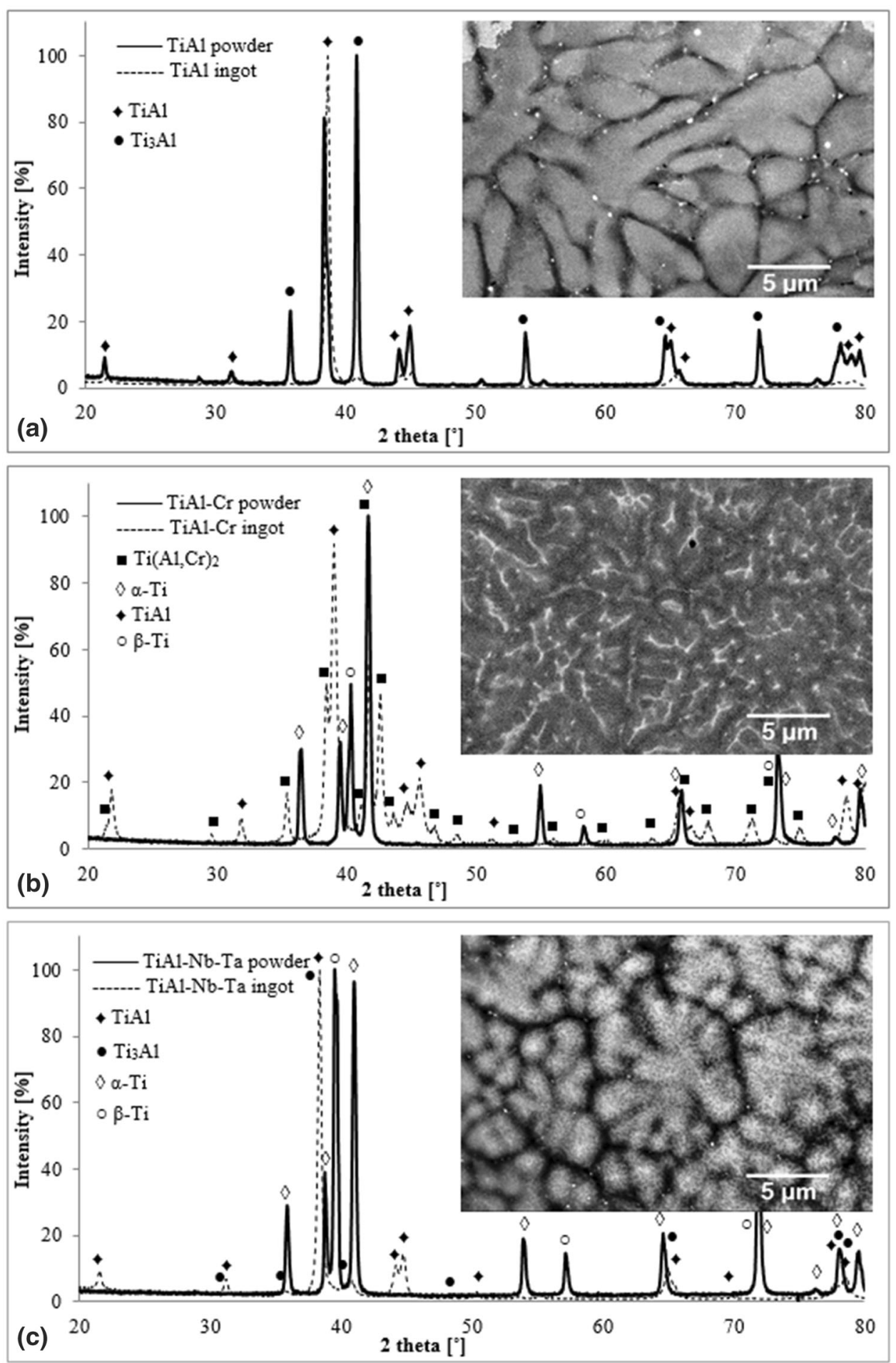
analysis (Fig. 2c) confirms the presence of $\alpha-\mathrm{Ti}(\mathrm{Nb}, \mathrm{Ta})$ and $\beta$ - Ti $(\mathrm{Nb}, \mathrm{Ta})$ phases.

\section{TiAl-(Cr, Nb, Ta) Coatings Characterization}

The cross sections of as-deposited coatings are shown in Fig. 3, and their characteristics are summarized in Table 4. Microstructures consisting of stacked particles were formed as a result of particles hitting the substrate during spraying. All coatings have a relatively low porosity located between the particles. The higher temperature of the in-flight particles in the HVOF technique enhances their oxidation and hence could hinder deformation to form good bonding between particles (Ref 44). Therefore, the porosity of WSed coatings was slightly lower. Deposition efficiency (DE) of all coatings prepared by HVOF was more than $50 \%$ higher than by WS process. This is because the temperature of powder particles during WS process is lower than that for HVOF and the number of powder particles in the solid state during spraying is higher (Ref 40). Furthermore, the low DE of WS is most likely related to preferential deposition of the smaller particles of the powder-the larger particles in WS were not heated enough to deform and adhere to the coating. In the HVOF coating, large particles appeared to have been heated enough both to deform and adhere to the coating, but still not enough to undergo significant deformation upon impact causing occurrence of the large lumpy "potato"-shaped splats in the coating. The poor deformation of these large particles could contribute to the higher porosity in the HVOF coatings.
TiAl WS
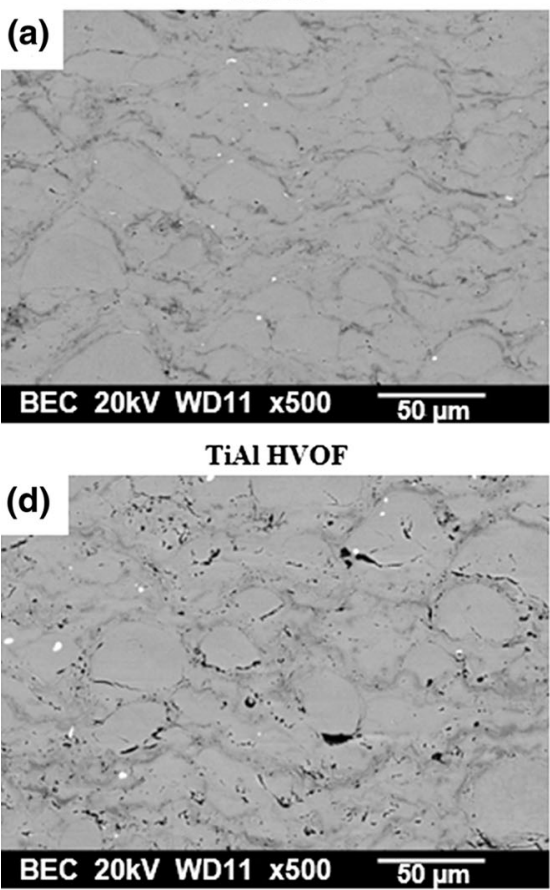

TiAl-Cr WS

(b)
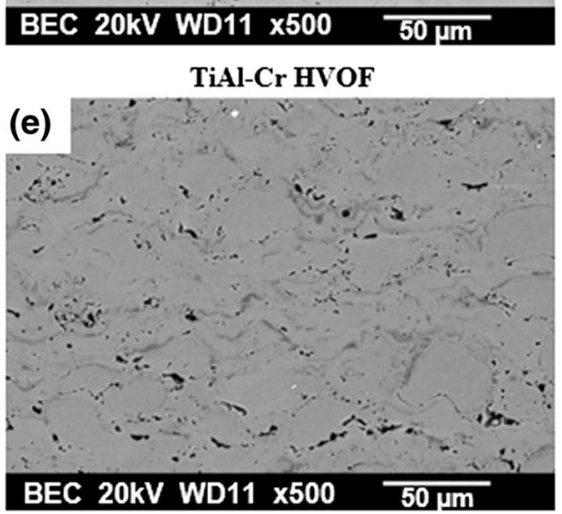

TiAl-Nb-Ta Ws

(c)
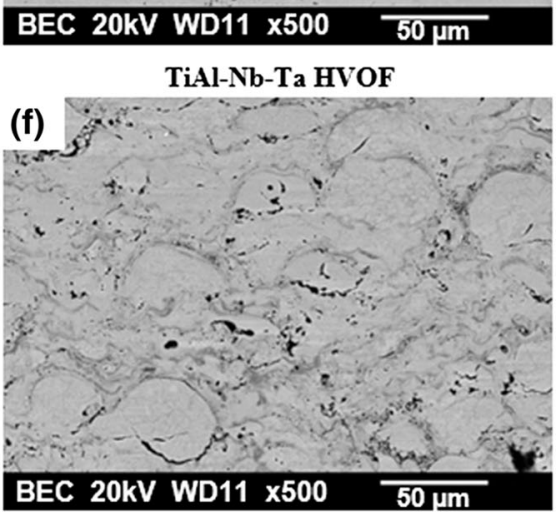

Fig. 3 SEM images of coatings' cross sections: (a) Ti-50Al, (b) Ti-51Al-12Cr, (c) Ti-46Al-8.5Nb-1Ta obtained by WS and (d) Ti-50Al, (e) Ti$51 \mathrm{Al}-12 \mathrm{Cr}$, (f) Ti-46Al-8.5Nb-1Ta obtained by HVOF

Table 4 Features of as-deposited coatings

\begin{tabular}{llccccc}
\hline Process & Coating & Thickness, $\mu \mathrm{m}$ & Porosity, $\%$ & Surface roughness $R_{a}, \mu \mathrm{m}$ & Vickers hardness, HV0.5 & Oxygen content, wt.\% \\
\hline WS & Ti-Al & 227 & 0.55 & 7.5 & $638 \pm 7$ & 3.4 \\
& TiAl-Cr & 238 & 0.06 & 7.7 & $656 \pm 4$ & 1.1 \\
& TiAl-Nb-Ta & 322 & 0.57 & 9.4 & $616 \pm 8$ & 2.4 \\
HVOF & Ti-Al & 256 & 1.43 & 10.1 & $595 \pm 10$ & 6.2 \\
& TiAl-Cr & 354 & 1.52 & 10.0 & $600 \pm 9$ & 6.9 \\
& TiAl-Nb-Ta & 541 & 1.45 & 10.1 & $659 \pm 10$ & 6.0 \\
\hline
\end{tabular}


The results of microhardness test with $500-\mathrm{g}$ loading showed no dependence on the spraying process. SEM observations revealed no indentation cracks. On the other hand, spraying process influenced the mean surface roughness $\left(R_{a}\right)$ which is higher for HVOF-see Table 4 . Coatings prepared by HVOF have higher $R_{a}$ than coatings produced by WS since the flame temperature during WS is lower and rebounding of larger particles during the spraying process is more likely, thereby resulting in decreasing of $R_{a}$.

The results show that oxygen content of WS coatings is about or less than a half of these by HVOF, indicating that powder oxidation was prevented by injection of cooling nitrogen gas in warm spraying. Moreover, the variation in nozzle length and spray distance also play a role in preventing oxidation. The WS nozzle was significantly longer than the HVOF one which protected the particles from air. Also, the spray distance in WS was dramatically shorter, limiting the exposure time in the air. Based on SEM pictures, it can be concluded that the increase in internal oxidation in HVOF coatings corresponds to the thicker dark area around each sprayed particle (dark gray layers surrounding particles).

XRD patterns taken from the surfaces of the coatings are shown in Fig. 4. These patterns reveal that as-sprayed TiAl contains mostly $\gamma$-TiAl and $\alpha_{2}-\mathrm{Ti}_{3} \mathrm{Al}$ phases (Fig. $4 \mathrm{a}$ ), while in TiAl-Cr and TiAl-Nb-Ta coatings, $\alpha$-Ti and $\beta$-Ti phases are observed, see Fig. 4(b) and (c). XRD patterns of WS and HVOF coatings indicate slight differences in phase composition in relation to the powder. As the gas-atomized powders possessed metastable phase composition, some changes in phase content could have place due to exposure to high temperature during spraying. Moreover, for all the coatings, broadening of XRD peaks occurred in comparison with the powders, which can be attributed to both the lattice distortion induced by spraying and formation of nano-sized regions. It should be noted that for the coatings obtained by HVOF, additional peaks from $\mathrm{TiO}$ or $\mathrm{TiO}_{2}$ were observed because of higher temperature during spraying. When particle temperature is high, particles are significantly oxidized and thick oxides formed around particles, see Fig. 3. During the oxidation process, the high affinity of TiAl- $(\mathrm{Cr}, \mathrm{Nb}, \mathrm{Ta})$ to oxygen and the high solid solubility of oxygen into titanium aluminides at elevated temperatures [about 13 and 3 at. $\%$ in $\mathrm{Ti}_{3} \mathrm{Al}$ and $\mathrm{TiAl}$ at $1100{ }^{\circ} \mathrm{C}$, respectively (Ref 45)] resulted in the formation of the $\mathrm{TiO}$ and $\mathrm{TiO}_{2}$. Furthermore, the results indicate that oxygen content increased about 15 times for HVOF coatings in relation to the initial content in the appropriate powders, see Table 4 .

\section{Phase Transformation Due to Oxidation Tests}

Before discussing the result of oxidation, it is noteworthy that the microstructure of coatings underwent an appreciable change due to the high-temperature exposure at $750{ }^{\circ} \mathrm{C}$ as evident from the XRD results summarized in Table 5 as well as the cross-sectional microstructures revealed in Fig. 5. For the TiAl coatings, XRD peaks mostly from $\gamma$-TiAl with a small amount of $\mathrm{Ti}_{3} \mathrm{Al}$ phase were detected indicating a phase transformation $\mathrm{Ti}_{3-}$ $\mathrm{Al} \rightarrow \gamma$-TiAl occurred. The retained $\alpha_{2}\left(\mathrm{Ti}_{3} \mathrm{Al}\right)$ phase was found to be segregated around particles boundaries (Fig. 5a). This segregation occurred due to $\mathrm{Al}$ consumption during oxidation tests. The TiAl-Cr coatings consisting of $\alpha$-Ti and $\beta$-Ti in the as-sprayed state transformed into a two-phase microstructure with a $\gamma$-TiAl matrix with precipitates of Laves phase $\mathrm{Ti}(\mathrm{Al}, \mathrm{Cr})_{2}$ during the oxidation test as shown in Fig. 5(b). The metastable as-sprayed microstructure of the TiAl-Nb-Ta coating also transformed to a microstructure mostly consisting of $\gamma$-TiAl as shown in Fig. 5(c).

\section{Results of Oxidation Tests}

Figure 6 shows the weight gained per unit surface area of the coated IMI 834 alloy after the isothermal oxidation test at $750{ }^{\circ} \mathrm{C}$ for $100 \mathrm{~h}$. The TiAl and TiAl-Nb-Ta coatings obtained by HVOF showed higher weight gain than the base IMI 834 substrate, whereas the same coatings by WS showed improved weight gain as compared to the substrate. The TiAl-Cr coatings showed the smallest weight gain. The coatings produced by WS generally exhibited significantly lower weight gain than HVOF, which exemplifies that spraying technique can influence the oxidation resistance of the sprayed coatings.

A comparison of specific mass gain curves of the same set of specimens during the cyclic oxidation at $750{ }^{\circ} \mathrm{C}$ for $100 \mathrm{~h}$ is shown in Fig. 7. While IMI 834 substrate showed a standard parabolic weight gain curve, rapid initial oxidation is clearly seen for the first cycle of all the coated specimens. A stable oxide scale that covers the entire surface seems to have formed at this temperature in the very first cycles. Once a stable oxide scale is formed, the subsequent oxidation is controlled by the rate of diffusion of oxygen ions through the oxide scale to the oxide-metal interface (Ref 46). At this point, a true parabolic oxidation behavior is observed with a nearly constant rate which confirms to the parabolic growth. The occurrence of the initial transient state which exhibits a fairly large oxidation rate followed by parabolic growth was confirmed by previous studies ( $\operatorname{Ref} 45,46)$.

The results also indicate that there were significant differences in the oxidation rate of the coatings. The TiAl 
Fig. 4 XRD patterns for coatings obtained by WS and HVOF from (a) Ti-50Al, (b) Ti$\mathrm{Al}-\mathrm{Cr}$ and (c) Ti-46Al-8.5Nb-

1Ta powders
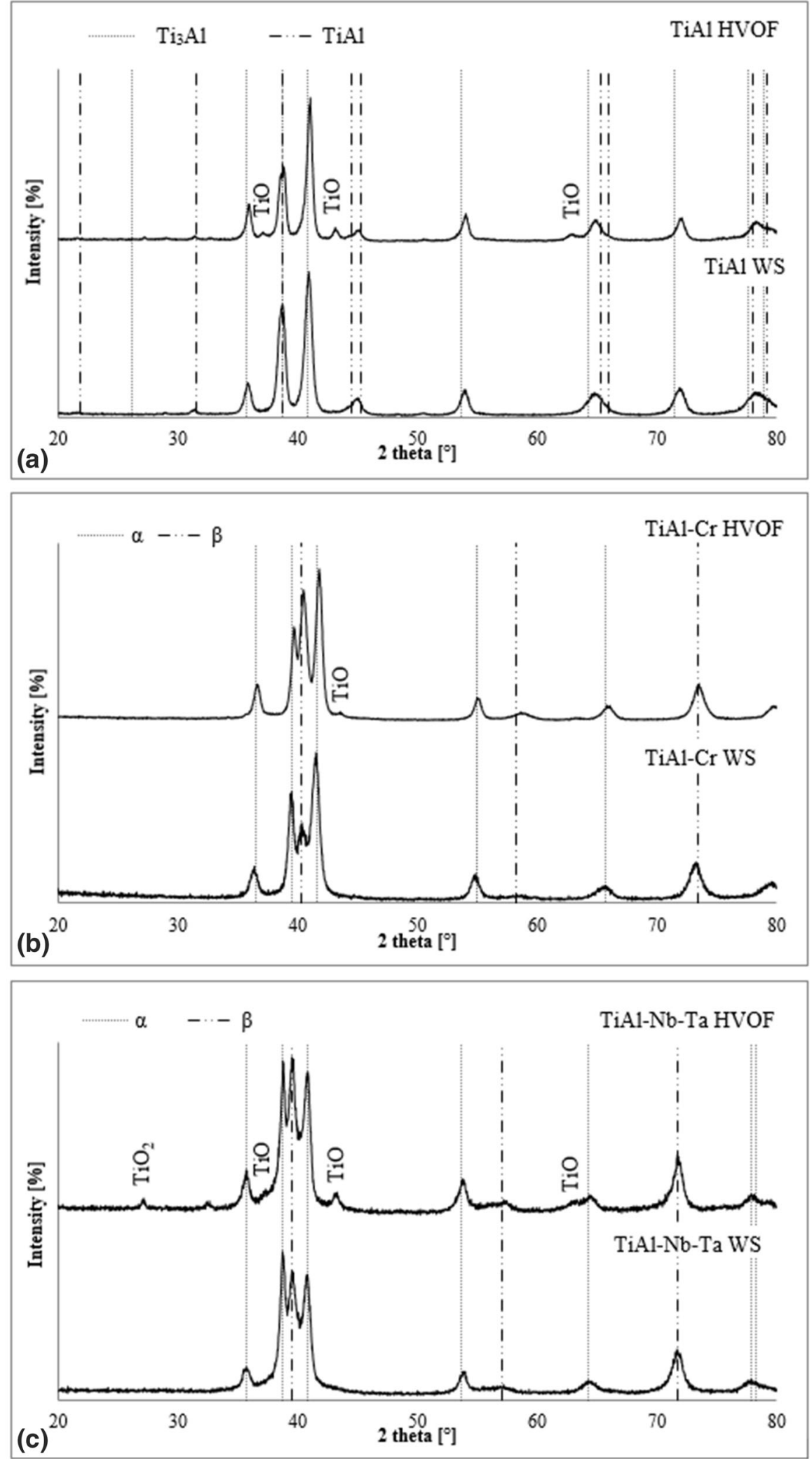

and TiAl-Nb-Ta coatings produced by HVOF process showed the poorest oxidation resistance with the total mass gain of 2.8 and $1.5 \mathrm{mg} \mathrm{cm}^{-2}$, respectively. Moreover, there was a clear sign of scale delamination for the TiAl-Nb-Ta coating after 40 cycles. These values are higher than the mass gain for uncoated IMI 834, which was $1.3 \mathrm{mg} \mathrm{cm}^{-2}$. 
Table 5 Characteristics of the coatings scales after isothermal and cyclic oxidation test at $750{ }^{\circ} \mathrm{C}$ for $100 \mathrm{~h}$ in air

\begin{tabular}{|c|c|c|c|c|c|c|c|}
\hline \multirow[t]{2}{*}{ Coating } & \multirow[t]{2}{*}{ Phases } & \multicolumn{3}{|c|}{ Isothermal oxidation } & \multicolumn{3}{|c|}{ Cyclic oxidation } \\
\hline & & Mass gain, $\mathrm{mg} \mathrm{cm}^{-2}$ & $\begin{array}{c}\text { Thickness, } \\
\mu \mathrm{m}\end{array}$ & $\begin{array}{c}\text { Phases, } \\
\mathrm{TiO}_{2} /\left(\mathrm{Al}_{2} \mathrm{O}_{3}\right. \\
\left.+\mathrm{TiO}_{2}\right) \text { ratio }\end{array}$ & Mass gain, $\mathrm{mg} \mathrm{cm}^{-2}$ & $\begin{array}{c}\text { Thickness, } \\
\mu \mathrm{m}\end{array}$ & $\begin{array}{c}\text { Phases, } \\
\mathrm{TiO}_{2} /\left(\mathrm{Al}_{2} \mathrm{O}_{3}\right. \\
\left.+\mathrm{TiO}_{2}\right) \text { ratio }\end{array}$ \\
\hline TiAl (WS) & $\begin{array}{c}\gamma-\mathrm{TiAl} \\
\alpha_{2}-\mathrm{Ti}_{3} \mathrm{Al}\end{array}$ & 1.12 & $3.2 \pm 0.5$ & $\begin{array}{l}\mathrm{TiO}_{2} \\
\mathrm{Al}_{2} \mathrm{O}_{3} \\
\mathrm{TiN} \\
\mathrm{Ti}_{2} \mathrm{AlN} \\
\gamma-\mathrm{TiAl} \\
{[0.73]}\end{array}$ & 1.213 & $2.1 \pm 0.4$ & $\begin{array}{l}\mathrm{TiO}_{2} \\
\mathrm{Al}_{2} \mathrm{O}_{3} \\
\mathrm{TiN} \\
\mathrm{Ti}_{2} \mathrm{AlN} \\
\gamma-\mathrm{TiAl} \\
{[0.76]}\end{array}$ \\
\hline TiAl (HVOF) & $\begin{array}{l}\gamma-\mathrm{TiAl} \\
\alpha_{2}-\mathrm{Ti}_{3} \mathrm{Al} \\
\mathrm{TiO} \\
\mathrm{TiO}_{2}\end{array}$ & 4.65 & $12.1 \pm 0.7$ & $\begin{array}{l}\mathrm{TiO}_{2} \\
\mathrm{Al}_{2} \mathrm{O}_{3} \\
\mathrm{TiN} \\
\mathrm{Ti}_{2} \mathrm{AlN} \\
\gamma-\mathrm{TiAl} \\
{[0.75]}\end{array}$ & 2.755 & $9.6 \pm 0.6$ & $\begin{array}{l}\mathrm{TiO}_{2} \\
\mathrm{Al}_{2} \mathrm{O}_{3} \\
\mathrm{TiN} \\
\mathrm{Ti}_{2} \mathrm{AlN} \\
\gamma-\mathrm{TiAl} \\
{[0.91]}\end{array}$ \\
\hline TiAl-Cr (WS) & $\begin{array}{c}\alpha-\mathrm{Ti} \\
\beta-\mathrm{Ti}\end{array}$ & 0.16 & $0.5 \pm 0.1$ & $\begin{array}{l}\mathrm{TiO}_{2} \\
\mathrm{Al}_{2} \mathrm{O}_{3} \\
\mathrm{Ti}_{2} \mathrm{AlN} \\
\gamma-\mathrm{TiAl} \\
\mathrm{Ti}(\mathrm{Al}, \mathrm{Cr})_{2} \\
{[0.63]}\end{array}$ & 0.507 & $0.4 \pm 0.1$ & $\begin{array}{l}\mathrm{TiO}_{2} \\
\mathrm{Al}_{2} \mathrm{O}_{3} \\
\mathrm{Ti}_{2} \mathrm{AlN} \\
\gamma-\mathrm{TiAl} \\
\mathrm{Ti}(\mathrm{Al}, \mathrm{Cr})_{2} \\
{[0.62]}\end{array}$ \\
\hline TiAl-Cr (HVOF) & $\begin{array}{l}\alpha-\mathrm{Ti} \\
\beta-\mathrm{Ti} \\
\mathrm{TiO}\end{array}$ & 1.44 & $0.6 \pm 0.1$ & $\begin{array}{l}\mathrm{TiO}_{2} \\
\mathrm{Al}_{2} \mathrm{O}_{3} \\
\mathrm{Ti}_{2} \mathrm{AlN} \\
\gamma-\mathrm{TiAl} \\
\mathrm{Ti}(\mathrm{Al}, \mathrm{Cr})_{2} \\
{[0.43]}\end{array}$ & 1.009 & $0.5 \pm 0.1$ & $\begin{array}{l}\mathrm{TiO}_{2} \\
\mathrm{Al}_{2} \mathrm{O}_{3} \\
\mathrm{Ti}_{2} \mathrm{AlN} \\
\gamma-\mathrm{TiAl} \\
\mathrm{Ti}(\mathrm{Al}, \mathrm{Cr})_{2} \\
{[0.97]}\end{array}$ \\
\hline TiAlNbTa (WS) & $\begin{array}{c}\alpha-\mathrm{Ti} \\
\beta-\mathrm{Ti}\end{array}$ & 1.38 & $1.1 \pm 0.4$ & $\begin{array}{l}\mathrm{TiO}_{2} \\
\mathrm{Al}_{2} \mathrm{O}_{3} \\
\mathrm{Ti}_{2} \mathrm{AlN} \\
\gamma-\mathrm{TiAl} \mathrm{Al} \\
\alpha_{2}-\mathrm{Ti}_{3} \mathrm{Al} \\
{[0.65]}\end{array}$ & 1.126 & $2.0 \pm 0.4$ & $\begin{array}{l}\mathrm{TiO}_{2} \\
\mathrm{Al}_{2} \mathrm{O}_{3} \\
\mathrm{Ti}_{2} \mathrm{AlN} \\
\gamma-\mathrm{TiAl} \\
\alpha_{2}-\mathrm{Ti}_{3} \mathrm{Al} \\
{[0.89]}\end{array}$ \\
\hline TiAlNbTa (HVOF) & $\begin{array}{l}\alpha-\mathrm{Ti} \\
\beta-\mathrm{Ti} \\
\mathrm{TiO} \\
\mathrm{TiO}_{2}\end{array}$ & 3.30 & $8.3 \pm 1.0$ & $\begin{array}{l}\mathrm{TiO}_{2} \\
\mathrm{Al}_{2} \mathrm{O}_{3} \\
\mathrm{Ti}_{2} \mathrm{AlN} \\
\gamma-\mathrm{TiAl} \\
\alpha_{2}-\mathrm{Ti}_{3} \mathrm{Al} \\
{[0.72]}\end{array}$ & 1.498 & $2.3 \pm 0.5$ & $\begin{array}{l}\mathrm{TiO}_{2} \\
\mathrm{Al}_{2} \mathrm{O}_{3} \\
\mathrm{Ti}_{2} \mathrm{AlN} \\
\gamma-\mathrm{TiAl} \\
\alpha_{2}-\mathrm{Ti}_{3} \mathrm{Al} \\
{[0.93]}\end{array}$ \\
\hline
\end{tabular}

Similar to the isothermal oxidation test, the coatings produced by WS generally exhibited significantly better oxidation resistance than the coatings prepared by HVOF and the lowest oxidation weight gain was measured for the TiAl-Cr coating by WS with the total mass gain of $0.5 \mathrm{mg} \mathrm{cm}^{-2}$.
It should be noted that the coated samples were tested in the as-sprayed condition so that, due to surface roughness effects, the actual exposed surface area of the coatings is significantly higher than that of the bare sample and also varies between the coatings as a function of their roughness. As such, the data plot the mass gain per nominal surface area of the coating based on the sample 

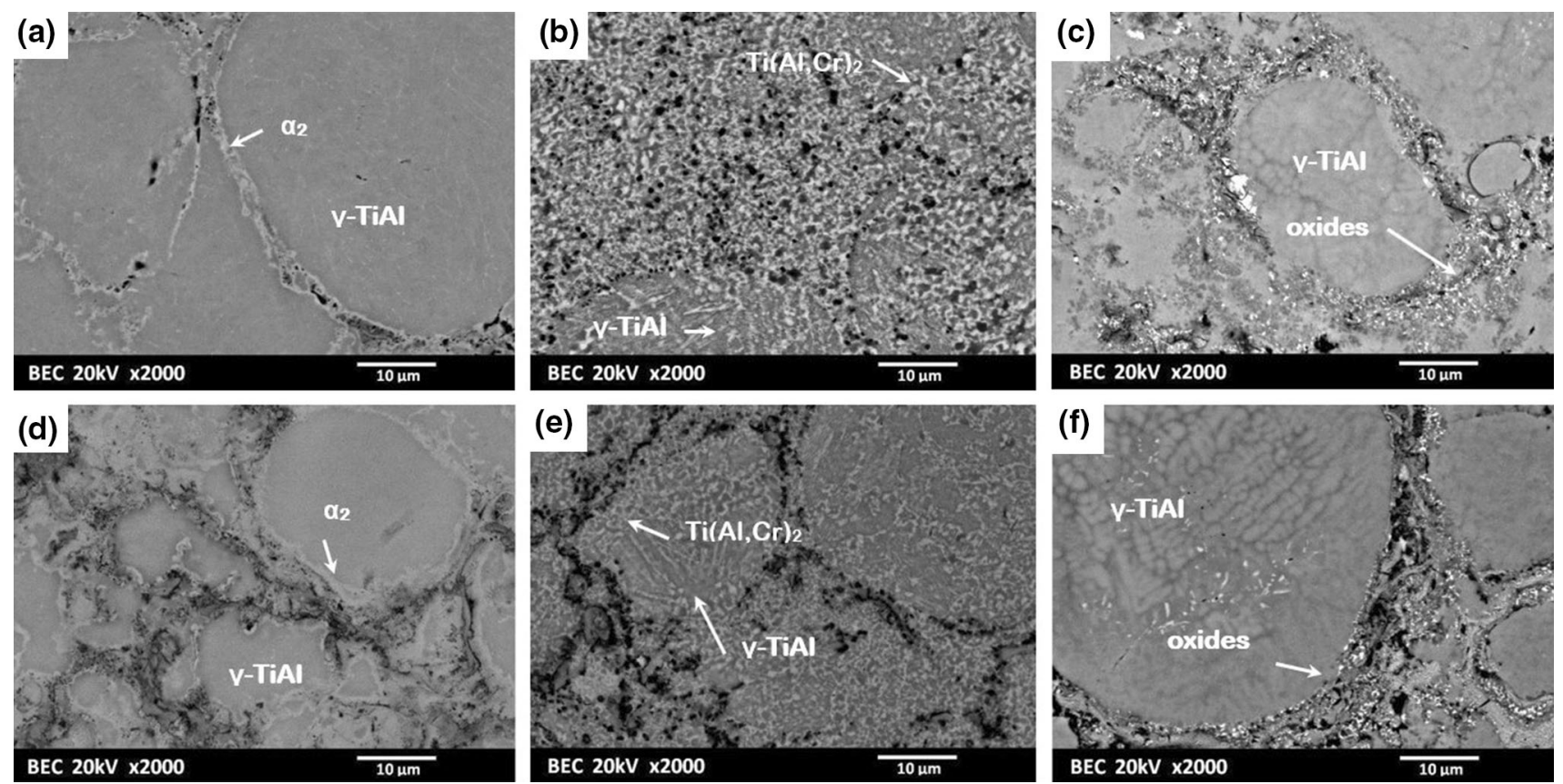

Fig. 5 SEM image of cross section of coatings produced by WS and HVOF after isothermal oxidation test at $750{ }^{\circ} \mathrm{C}$ during $100 \mathrm{~h}$ : (a) Ti-50Al WS, (b) Ti-51Al-12Cr WS, (c) Ti-46Al-8.5Nb-1Ta WS, (d) Ti-50Al HVOF, (e) Ti-51Al-12Cr HVOF, (f) Ti-46Al-8.5Nb-1Ta HVOF

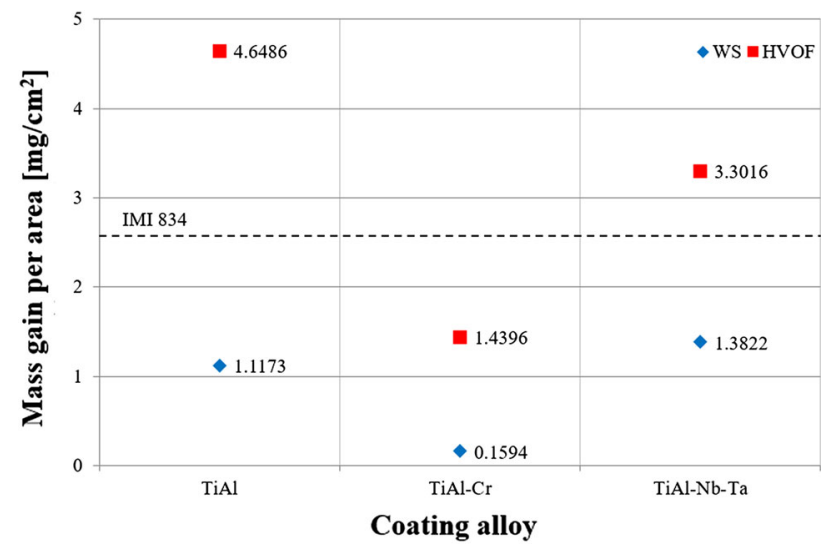

Fig. 6 Weight gain for IMI 834 with TiAl-(Cr, Nb, Ta) by WS and HVOF isothermally oxidized at $750{ }^{\circ} \mathrm{C}$ for $100 \mathrm{~h}$ in air (dashed line on chart corresponds to weight gain for bare IMI 834)

dimensions, not the true exposed surface area. Nevertheless, taking into account the thickness of the oxide layer (that will be discussed in the next part of this article), the greater weight gain of the HVOF coatings is clearly seen. The XRD results confirm that the oxide scales contain $\mathrm{TiO}_{2}$ and $\mathrm{Al}_{2} \mathrm{O}_{3}$, in agreement with the observation made in previous studies (Ref 46-48). It is worth to add that higher concentration of titania was formed on coatings prepared by HVOF process after both isothermal and cyclic oxidation-see Table 5. Such phases, as well as TiN and $\mathrm{Ti}_{2-}$ AlN, were also identified [which is in agreement with (Ref $48,49)$ ] with some peaks from the underlying intermetallic coating, e.g., $\gamma$-TiAl and $\alpha_{2}-\mathrm{Ti}_{3} \mathrm{Al}$. It is also important to note that the oxidation rates of the studied coatings were higher in comparison with the bulk specimen with the same composition (Ref 30, 50). Therefore, there are at least two or three points that need to be discussed for the results of the oxidation tests. The first is why the WS coatings performed better than the HVOF coatings, and the second is the reason behind the relatively large initial oxidation. Another point is that oxidation of our sprayed coatings was generally larger than the reported bulk materials in the literature, which can be connected to the first two points. Samples after testing were observed and analyzed to elucidate the oxidation behavior of these coatings and possibly understand these points.

\section{Observation and Analysis of Oxide Scales}

Figure 8 shows the surface morphology and cross sections of the TiAl coatings obtained by WS $\backslash$ HVOF after isothermallcyclic oxidation tests, whereas the results of XRD measurements are summarized in Table 5. On the coatings surfaces were observed $\mathrm{TiO}_{2}$ crystals as numerous short columns (Fig. 8a and b), which were larger for the HVOF ones. Moreover, as it was confirmed by Becker et al. (Ref 51), the size of $\mathrm{TiO}_{2}$ crystals increases with increasing oxidation time and scale thickness, indicating that these crystals grew by outward cation diffusion. Cross-sectional images of the scales show that the scale thickness of the HVOF coatings was much larger than those of the WS coatings by a factor of about four. Cracks were also found 
Fig. 7 Specific weight variations during thermal cyclic oxidation of uncoated and coated IMI 834 specimens at $750{ }^{\circ} \mathrm{C}$

Fig. 8 SEM images of the surface morphologies and cross sections of Ti-50Al coatings after oxidation test at $750{ }^{\circ} \mathrm{C}$ for $100 \mathrm{~h}$ in air: (a) produced by WS after isothermal oxidation, (b) produced by HVOF after isothermal oxidation,

(c) produced by WS after cyclic oxidation, (d) produced by HVOF after cyclic oxidation
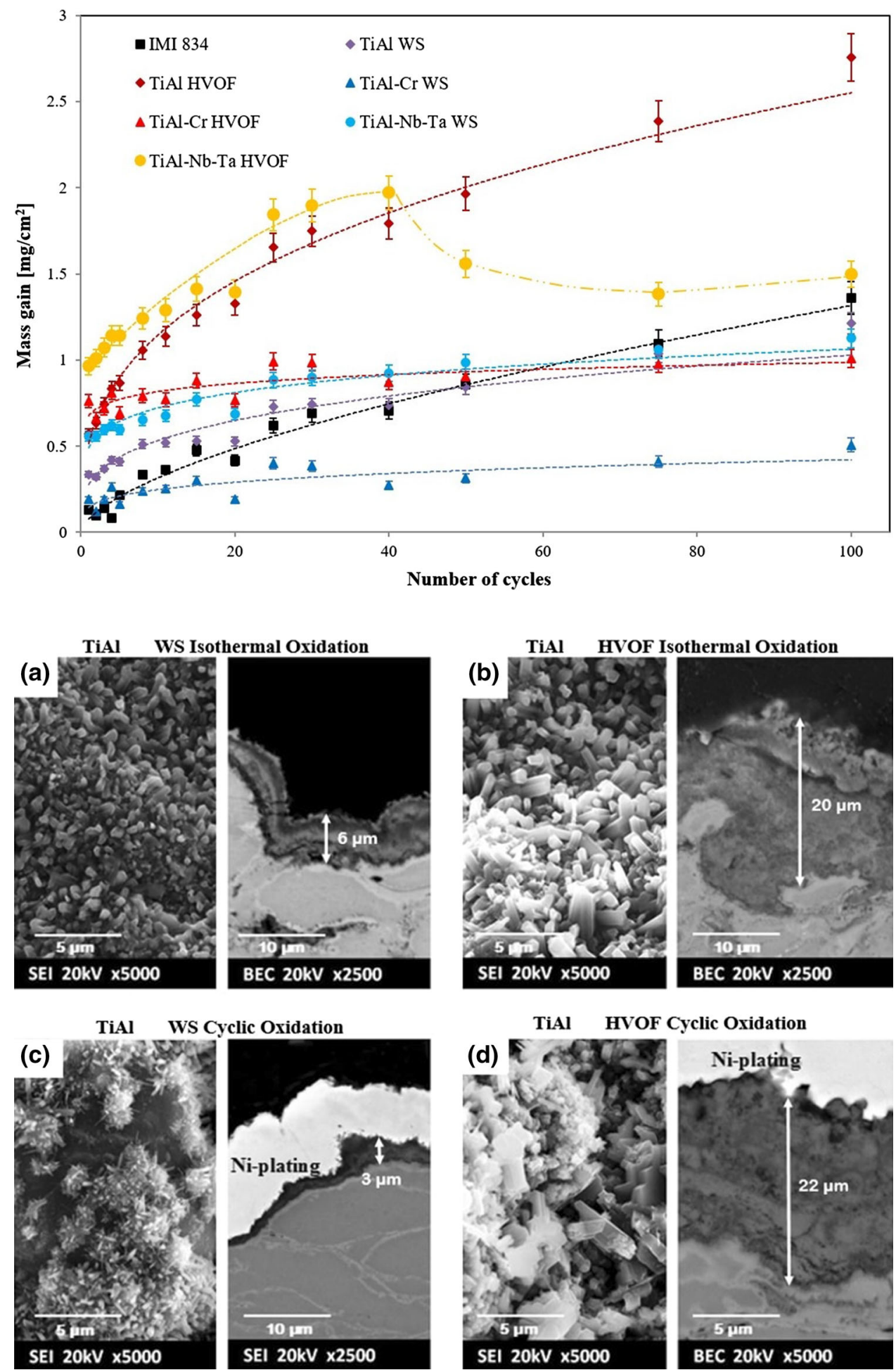

in the scales on both coatings formed during isothermal oxidation, which might be caused by a rapid diffusion of $\mathrm{Ti}$ to $\mathrm{TiO}_{2}$, resulting in voids formation by the Kirkendall mechanisms and leading to cracks propagation (Ref 46). In Fig. 9, the $\mathrm{Al}$ and Ti EDS maps appear to suggest there is an outer Ti-rich layer containing $\mathrm{TiO}_{2}$, but also some nitrides based on the $\mathrm{N}$ map and correlating the features with the BSE image. Immediately below this, there is a bright band in the Al EDS suggesting a band of $\mathrm{Al}_{2} \mathrm{O}_{3}$. This correlates with the darker contrast feature in the BSE image (which correlates with $\mathrm{Al}_{2} \mathrm{O}_{3}$ having a lower backscatter electron coefficient (based on lower atomic mass) than 

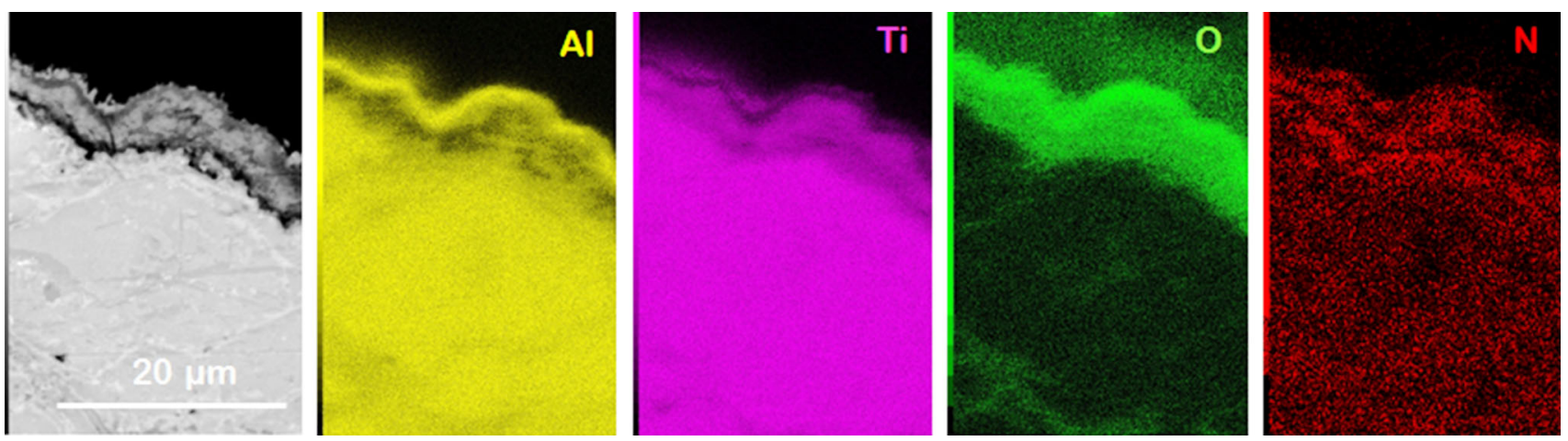

Fig. 9 EDS x-ray mapping showed layers of oxides on Ti-50Al coating in WS process after isothermal oxidation test

$\mathrm{TiO}_{2}$ ) and the dark band in the $\mathrm{Ti}$ and $\mathrm{N}$ maps. Below the Al-rich layer are mixed oxides, but these appear to be dominated by $\mathrm{Ti}$ phases as the $\mathrm{Al}$ image implies low $\mathrm{Al}$ content through this region. The N-rich phases appear to be distributed in this mixed zone with some of the brightest patches of N-rich material within the surface of the coating, beneath the oxide scale.

At the oxide-metal interface, aluminum-depleted zone (titanium-enriched) with a composition close to $\mathrm{Ti}_{3} \mathrm{Al}$ is observed. The existence of the nitride layer as well as Aldepleted zone was confirmed by a number of authors who have studied oxidation behavior of TiAl intermetallics (Ref $48,49)$. It has also been assumed that the transient formation of titanium nitrides at the beginning of oxidation prevents the development of a continuous protective $\mathrm{Al}_{2} \mathrm{O}_{3}$ layer and therefore leads to the detrimental effect of nitrogen-containing atmospheres. The destruction of the initial protective $\mathrm{Al}_{2} \mathrm{O}_{3}$ layer is associated with oxidation of the initially formed Ti-rich nitride into $\mathrm{Ti}$ oxide. The destruction of the protective Al-rich scale causes for a given oxidation time the oxidation rates to be larger resulting in a strong increase in weight in this initial state. The oxidation rate decreases during the next stage when a scale structure is formed which consists of an outer $\mathrm{TiO}_{2}$ scale followed by a mixture of $\mathrm{TiO}_{2}$ and $\mathrm{Al}_{2} \mathrm{O}_{3}$. Furthermore, by $\mathrm{Al}_{2} \mathrm{O}_{3}$ enrichment in the outer part of the mixed oxide layer, the effective diffusion rate becomes more and more reduced, ending up with the formation of protective oxide scale by closing up of the $\mathrm{Al}_{2} \mathrm{O}_{3}$ particles. While long-term oxidation testing (reaching several hundred hours), the $\mathrm{Al}_{2} \mathrm{O}_{3}$ barrier dissolves and reprecipitates in the outer oxide scale as discontinuous blocky particles, which might lead to breakaway oxidation with enhanced weightgain rates (Ref 51, 52).

As compared to the TiAl coatings, the oxide scales formed on the TiAl-Cr coatings were more compact and continuous as shown in Fig. 10. Moreover, it is clearly seen that these oxides are dramatically thinner than ones formed on the TiAl coatings with the thickness of $0.5 \mu \mathrm{m}$ versus
$6 \mu \mathrm{m}$, e.g., for WSed coatings after isothermal oxidation. XRD patterns show that $\mathrm{Al}_{2} \mathrm{O}_{3}$ is richer in these scales whereas $\mathrm{TiO}_{2}$ appeared as whiskers, bigger for the HVOF coatings and after isothermal oxidation test. The $\mathrm{TiO}_{2}$ oxide crystals are relatively insignificant in size for both the WS and HVOF coatings, in comparison with the crystals on the TiAl ones, which are a consequence of the thin oxide scales. The scales formed during isothermal and cyclic oxidation tests are very thin. No Kirkendall voids appeared at the coating/substrate interface. Good oxidation resistance of TiAl-Cr coatings is generally consistent with the findings by Brady et al, who concluded that $\mathrm{Cr}$ beneficially influences oxidation resistance by the formation of a Laves phase $\mathrm{Ti}(\mathrm{Cr}, \mathrm{Al})_{2}$ (Ref 25). Excellent oxidation resistance of this coating is connected with the high stability of the Laves phase at the temperature of $750{ }^{\circ} \mathrm{C}$ as well as its very low affinity for oxygen. Except that, the Laves phase possesses low oxygen permeability and is capable to form a protective alumina scale; there are also other factors that certainly play a role in the $\mathrm{Cr}$ effect. Particularly, it has been assumed that $\mathrm{Cr}$ addition to TiAl may affect the formation of nitrides during oxidation in the air (Ref 53). It should be pointed out that fine cracks were found through thickness of these coatings, however, after the tests (not shown in Fig. 10).

The morphology of oxides on the TiAl-Nb-Ta coatings was very different from those of TiAl and TiAl-Cr as shown in Fig. 11. No $\mathrm{TiO}_{2}$ whiskers or columns were observed. The EDS analysis not shown here revealed that the scale consisted of an outer layer of $\mathrm{Al}_{2} \mathrm{O}_{3}$, an intermediate layer consisting of $\mathrm{TiO}_{2}$ and an inner layer of nitrides together with niobium and tantalum particles at the scale/coating interface. The oxide scale appeared adherent to the coatings. The oxide scales after the cyclic oxidation test were thinner for both WS and HVOF coatings than after isothermal oxidation.

The oxide scales of oxidized TiAl-Nb-Ta coatings contain mainly $\alpha-\mathrm{Al}_{2} \mathrm{O}_{3}$ as well as $\mathrm{TiO}_{2}$. The EDS analysis shows that the $\mathrm{Ti}$ concentration decreases gradually toward 
Fig. 10 SEM images of surface morphologies and cross sections of Ti-51Al-12Cr coatings after oxidation test at $750{ }^{\circ} \mathrm{C}$ for $100 \mathrm{~h}$ in air: (a) produced by WS after isothermal oxidation, (b) produced by HVOF after isothermal oxidation,

(c) produced by WS after cyclic oxidation, (d) produced by HVOF after cyclic oxidation
Fig. 11 SEM images of surface morphologies and cross sections of Ti-46Al-8.5Nb-1Ta coatings after oxidation test at $750{ }^{\circ} \mathrm{C}$ for $100 \mathrm{~h}$ in air: (a) produced by WS after isothermal oxidation, (b) produced by HVOF after isothermal oxidation,

(c) produced by WS after cyclic oxidation, (d) produced by HVOF after cyclic oxidation
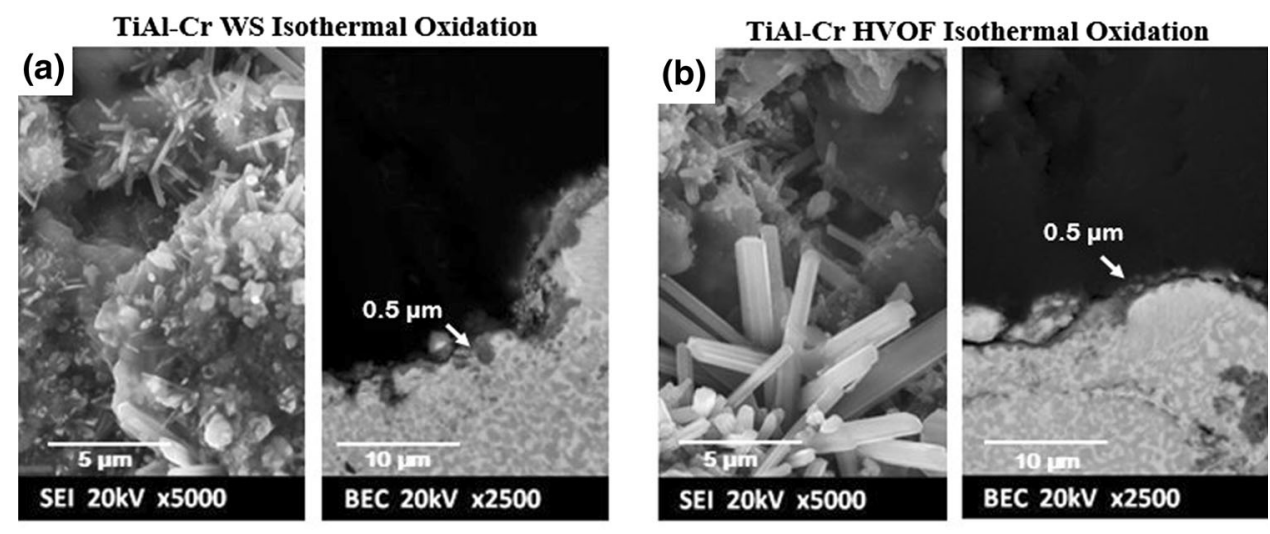

TiAl-Cr WS Cyclic Oxidation
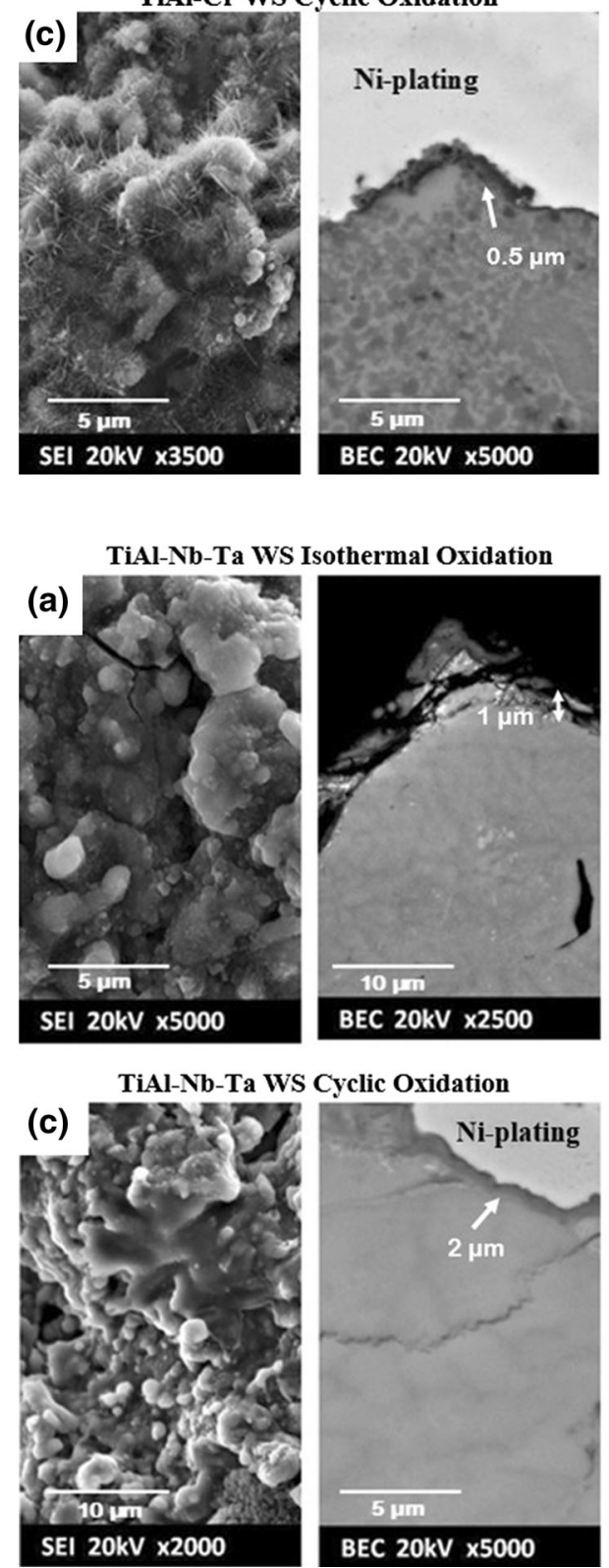
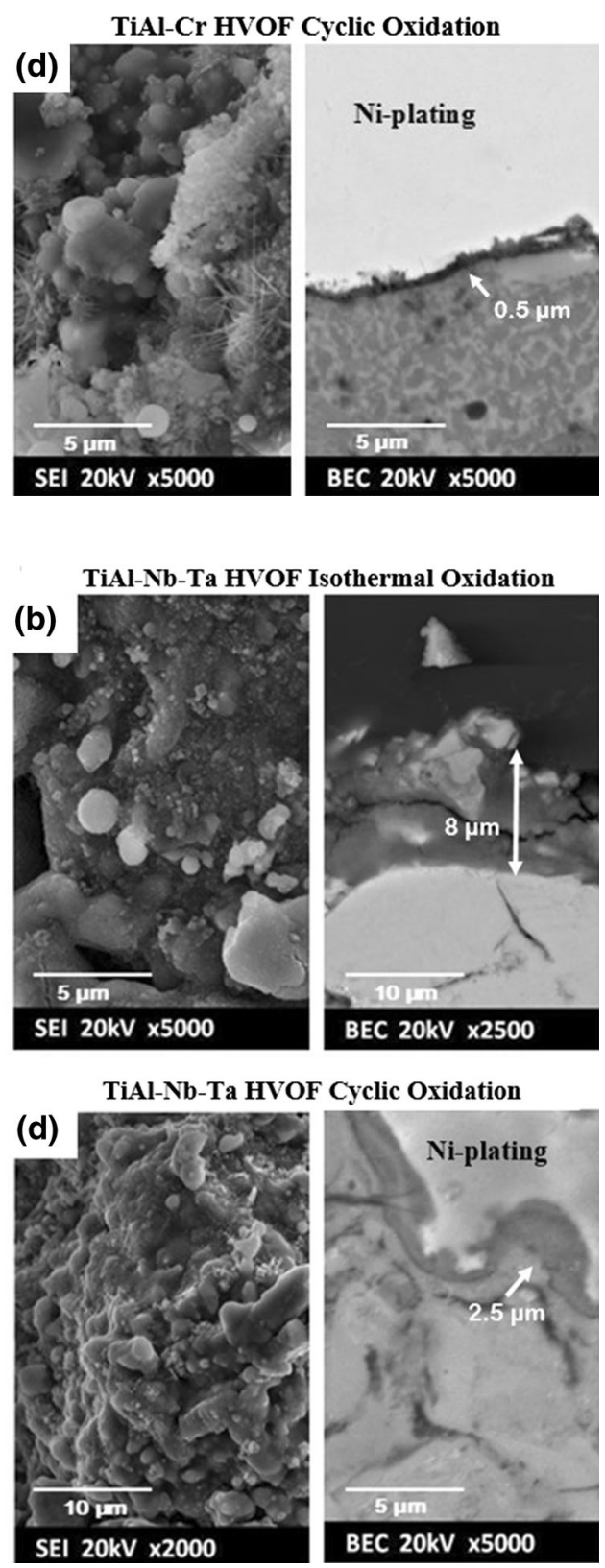
the coating, while the $\mathrm{Al}$ concentration decreases from the coating to the top of scale, see Fig. 12. Furthermore, the oxide scales were found to consist of an Al-rich top layer without the detectable amount of $\mathrm{Nb}$ and $\mathrm{Ta}$. Underneath, a $\mathrm{Ti}-(\mathrm{Nb}, \mathrm{Ta})$-rich sublayer was detected, suggesting that both $\mathrm{Nb}$ and $\mathrm{Ta}$ are incorporated in the $\mathrm{TiO}_{2}$ lattice, which is in good agreement with findings by Pfeiler et al. (Ref 54). Beneath, there is dense sublayer composed mainly of $\mathrm{Ta}$, $\mathrm{Ti}$ and $\mathrm{O}$. Under the defined oxidation conditions, nitride layer on the scale/coating interface has been observed. Nitrides corresponding to $\mathrm{TiN}$ and $\mathrm{Ti}_{2} \mathrm{AlN}$ were also detected by XRD. No cracks through the coatings were observed after the isothermal or cyclic oxidation tests.

Summarizing, the results of oxidation tests showed similar oxidation behavior for all coatings, significant mass gain in the very first cycles and successive oxidation in further cycles. It should be pointed, however, that the alloying elements affected the composition of each oxide scale and promoted the formation of $\alpha-\mathrm{Al}_{2} \mathrm{O}_{3}$. Furthermore, more importantly, all WSed coatings exhibited better oxidation resistance than ones produced by HVOF.

\section{Discussion}

As it was aforementioned, all WS coatings tested in our research performed better than the HVOF ones. Furthermore, it is commonly observed that there is a performance gap between the oxidation resistance of thermally sprayed coatings and the equivalent bulk material (e.g., mass gain for bulk Ti-48Al-8Nb is about 0.1 and $0.15 \mathrm{mg} \mathrm{cm}^{-2}$ during isothermal and cyclic oxidation at $750{ }^{\circ} \mathrm{C}$ for $100 \mathrm{~h}$, respectively (Ref 55), that is, about one order of magnitude lower than that for coatings produced by thermal spraying from powders with similar composition, see Table 5). The lower oxide growth rate for WS coatings and bulk materials can be explained by the several aspects as follows.

1. The first point may be due to the significantly modified microstructure of the sprayed coatings. However, currently, there is no detailed understanding of which aspects of microstructural modification are primarily responsible for this performance gap. This difference in oxidation performance is generally attributed to the inhomogeneous coating structure primarily caused by pores and oxides formed during coating deposition, as well as the elemental segregation arising from the rapidly solidified structure. The increase in the oxidation rate in thermally sprayed coatings compared to bulk materials with the same composition may be caused by the existence of $\mathrm{TiO}_{2}$ formed by $\mathrm{Ti}$ oxidation during thermal spraying. In particular, the high reactivity of $\mathrm{Ti}$ with oxygen makes the formation of $\mathrm{TiO}_{2}$ easier. Ti oxide was also observed by XRD in the study on titanium carbide- and boride-based coatings after the spraying (Ref 56). In, addition, Dewald et al. (Ref 31) indicated that an $\mathrm{L}_{2}(\mathrm{Al}, \mathrm{Cr})_{3} \mathrm{Ti}$ coating produced by thermal spraying exhibits high oxidation rate as compared to the alloys with the same composition. Therefore, it is elucidated that the increase in the oxidation rate of TiAl-based coatings results from the formation of $\mathrm{TiO}_{2}$ in the coating layer, thus facilitating oxygen diffusion at the interface of the as-sprayed coatings as the splat-splat bonding is prevented by these oxides. While the coatings are dense at ambient temperature, thermal expansion may lead to a slight opening up of the splat boundaries sufficient for oxygen diffusion at high temperature. It would only require a small extent of this effect to massively increase the exposed surface area and account for the rapid initial rate of mass gain prior to the splat boundaries being sealed up by internal oxidation. To reduce the oxidation rate of such coatings, the suppression of Ti-oxide formation during deposition is desired ( $\operatorname{Ref} 31)$. Moreover, Mori et al. reported that for CoNiCrAlY coatings sprayed by WS and HVOF, WS coatings performed better in an oxidation test at $1150{ }^{\circ} \mathrm{C}$. The result was explained by the difference in the amount of metallic $\mathrm{Al}$ in the sprayed coatings. For the HVOF coating, the amount
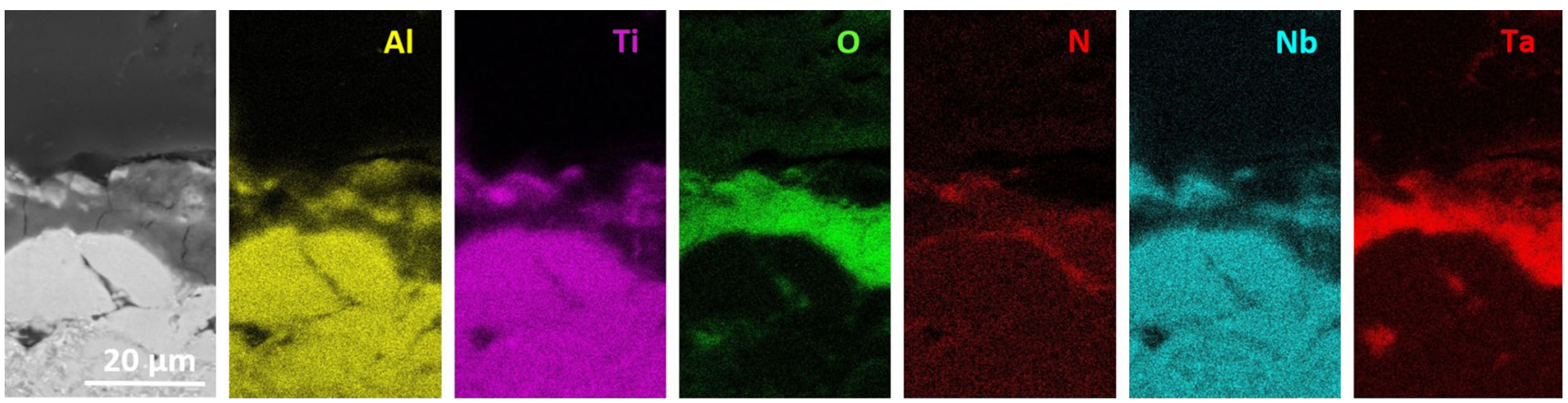

Fig. 12 EDS x-ray mapping showed layers of oxides on Ti-46Al-8.5Nb-1Ta coating in HVOF process after isothermal oxidation test 
of oxidation of $\mathrm{Al}$ was larger during spraying and the so-called Al-rich $\beta$-phase depletion proceeded faster, resulting in the earlier formation of spinel oxides other than the compact $\mathrm{Al}_{2} \mathrm{O}_{3}$ scale. It was reported that the increase in the oxidation rate results in the decrease in Al composition in the coatings and what is more the thicker oxides induce lower resistance to thermal stress (Ref 57).

2. Better oxidation resistance of WSed coatings than ones produced by HVOF could be explained also by higher porosity of the latter as it was confirmed that many pores exist in thermally sprayed TiAl-based coatings, especially by using HVOF, see Fig. 3. Pores in the coatings may play a role as diffusion paths for oxygen and induces partially internal oxidation; therefore, the increase in the oxidation rate in thermally sprayed TiAl coatings may result from not only $\mathrm{Ti}$ oxidation during spraying but also the existence of many pores in the coatings (Ref 30, 58). Furthermore, pores inside the HVOF coatings are the main transport path of oxygen ion-diffusion of oxygen ion and other corrosive species is much faster in pores than in metal and oxide scale. The porosity of the coating allowed oxygen penetrates the coating, which oxidized the splat boundaries, indeed that was observed at the poor particle-particle interface after the long-term exposure as can be seen in Fig. 3, 8, 10 and 11.

3. Furthermore, both WS and HVOF coatings were tested in the as-sprayed condition without any surface polishing. As it is provided in Table 4, surface roughness of the coatings produced by HVOF was higher than the WS coatings. It is known that the surface roughness plays a role in the high-temperature resistance of various materials such as $\mathrm{Ni}, \mathrm{Fe}-\mathrm{Cr}-\mathrm{Al}$, $\mathrm{Fe}-\mathrm{Al}$ (Ref 59-61). The composition of the oxide scale and the scale thickness were reported to be different depending on the starting sample surface finish-a faster oxidation rate is seen for greater surface roughness. Also, larger oxide particles were observed for coatings with higher surface roughness. The lower oxide growth rate for WSed coatings can be explained by the two aspects as follows. Firstly, the HVOF coating has the higher roughness, so it has larger surface areas to expose to air. Hence, the larger surface areas result in the higher mass change. Secondly, the small particles with quite weak bonding on the surface of the HVOF coatings can be observed. It has been reported that the weak bonding between the small particles and the underlying splat in thermally sprayed coatings limit or delay the diffusion of Al to small particles surface after $\mathrm{Al}$ depletion occurred in the particles (Ref 62). It is the same condition of HVOF
TiAl-based coatings. Therefore, Ti oxides grow fast in the small particles.

\section{Conclusion}

In the present study, three TiAl-based alloys, i.e., Ti$50 \% \mathrm{Al}$, Ti-51\%Al-12\%Cr, Ti-46\%Al-8.5\% Nb-1\% Ta in at.\%, were gas-atomized into spherical powders and thermally sprayed to form coatings by two atmospheric spray processes, i.e., commercial HVOF and a modified HVOF apparatus so-called warm spray (WS). Although the assprayed Ti-50\%Al, Ti-51\%Al-12\%Cr, Ti-46\%Al-8.5\% Nb$1 \%$ Ta coatings all exhibited metastable crystal structures inherited from the feedstock powders, they readily transformed to the stable microstructure during oxidation exposure at $750{ }^{\circ} \mathrm{C}$. The temperature during spraying had a significant influence on the microstructure and in-flight oxidation of these coatings. Use of WS significantly prevented the in-flight oxidation of powder as compared to HVOF, i.e., the oxygen contents in the WS coatings were about 40 to $55 \%$ for all composition of the corresponding HVOF coatings. The deposition efficiency, however, had to be sacrificed for WS by about $50 \%$ as compared to HVOF. Due to this and possibly with the difference in surface roughness, the WS coatings of the three compositions gave better oxidation resistance as compared to the corresponding HVOF coatings in both isothermal and cyclic oxidation tests at $750{ }^{\circ} \mathrm{C}$.

Among the three compositions tested, TiAl-Cr coatings exhibited the highest oxidation resistance with the mass gains at least ten times lower than that for the base titanium alloy IMI 834. The slow oxide growth rates observed for the TiAl-Cr intermetallic layers were associated with the formation of a thin scale established by the Laves phase$\mathrm{Ti}(\mathrm{Al}, \mathrm{Cr})_{2}$. Addition of 12 at.\% of chromium, however, induced cracking in the coatings under cyclic thermal loading due to their brittle nature. Cracks expose the Tialloy beneath coating for oxygen and may cause severe oxidation of the substrate in a long run. The coatings with niobium and tantalum showed no cracks in the coatings after the oxidation tests, indicating their better mechanical properties, and the oxidation rate of this alloy coating by WS was very low. The high initial oxidation, however, needs to be studied further. Scales were found adherent to the coatings too.

Modified HVOF method-warm spray-provided seemingly more protective coating characterized by both good oxidation resistance and compatibility between the substrate material-IMI 834. Addition of niobium and tantalum did not affect oxidation resistance of the intermetallic compound for an early stage of oxidation; 
nevertheless, $\mathrm{Nb}$ and $\mathrm{Ta}$ are believed to improve longlasting protection against oxidation, due to formation of dense scale and "doping effect", and can be expected to serve as an oxidation-resistant coating in the future thermal barrier coating system for titanium alloys.

Acknowledgment The authors are grateful to Mr. Takaaki Hibaru of the Materials Manufacturing and Engineering Station, NIMS, for producing the alloy ingots. Mr. Toshio Hiraoka of the High-Temperature Materials Unit, NIMS, is thanked for operating the thermal spray equipment. The results presented in this paper have been obtained during Ph.D. studies at Warsaw University of Technology, Faculty of Materials Science and Engineering, Division of Materials Design under WUT-NIMS Joint Graduate Program.

Open Access This article is distributed under the terms of the Creative Commons Attribution 4.0 International License (http://crea tivecommons.org/licenses/by/4.0/), which permits unrestricted use, distribution, and reproduction in any medium, provided you give appropriate credit to the original author(s) and the source, provide a link to the Creative Commons license, and indicate if changes were made.

\section{References}

1. J.C. Williams and E.A. Starke, Progress in Structural Materials for Aerospace Systems, Acta Mater., 2003, 51, p 5775-5799

2. C. Leyens, Advanced Materials and Coatings for Future Gas Turbine Applications, in 24th International Congress of the Aeronautical Sciences, 2004

3. I.J. Polmear, Light Alloys: Metallurgy of the Light Metals, 3rd ed., Butterworth Heinemann, London, 1995

4. S. Naka, Advanced Titanium-Based Alloys, Curr. Opin. Solid State Mater. Sci., 1996, 1, p 333-339

5. K. Firm, R. Boyer, and G. Welsch, Materials Properties Handbook: Titanium Alloys, R. Boyer, G. Welsch, and E.W. Collings, Ed., ASM International, Materials Park, 1994

6. K.V.S. Srinadh and V. Singh, Oxidation Behaviour of the near Aplha Titanium Alloy IMI, 834, Bull. Mater. Sci., 2004, 27(4), p 347-354

7. H.L. Du, P.K. Datta, D.B. Lewis, and J.S. Burnell-Gray, Enhancement of Oxidation/Sulphidation Resistance of Ti and Ti6Al-4 V Alloy by HfN Coating, Mater. Sci. Eng. A, 1996, 205, p 199-208

8. A.K. Gogia, High-Temperature Titanium Alloys, Def. Sci. J., 2005, 55(2), p 143-173

9. R.K. Clark, G.R. Cunnington, and K.E. Wiedemann, Experimental Evaluation of Low-Catalysis Coatings for Hypersonic Vehicle Applications, Exp. Therm. Fluid Sci., 1993, 7, p 156

10. S. Fujishiro and D. Eylon, Effect of Pt Ion Plating on the Creep Behavior of Alpha Ti, Scr. Metall., 1979, 13(79), p 201-203

11. D.W. McKee and K.L. Luthra, Plasma-Sprayed Coatings for Titanium Alloy Oxidation Protection, Surf. Coat. Technol., 1993, 56(84), p 109-117

12. S.L. Draper, D. Krause, B. Lerch, I.E. Locci, B. Doehnert, R. Nigam, G. Das, P. Sickles, B. Tabernig, N. Reger, and K. Rissbacher, Development and Evaluation of TiAl Sheet Structures for Hypersonic Applications, Mater. Sci. Eng. A, 2007, 464, p 330342

13. G.P. Chaudhari and V.L. Acoff, Titanium Aluminide Sheets Made Using Roll Bonding and Annealing Reaction, Intermetallics, 2010, 18, p 472-478
14. R.L. Fleischer, High-Strength, High-Temperature Intermetallic Compounds, J. Mater. Sci., 1987, 22, p 2281-2288

15. S.C. Huang and J.C. Chesnutt, Gamma TiAl and Its Alloys, Intermetallic Compounds, J.H. Westbrook and R.L. Fleischer, Ed., Wiley, New York, 1995

16. L.H. Bennett, T.B. Massalski, J.L. Murray, and H. Baker, Binary Alloy Phase Diagrams, ASM, Materials Park, 1986

17. F. Appel and R. Wagner, Microstructure and Deformation of Two-Phase $\gamma$-Titanium Aluminides, Mater. Sci. Eng. R Rep., 1998, 22(5), p 187-268

18. H.A. Lipsitt, D. Shechtman, and R.E. Schafrik, The Deformation and Fracture of TiAl at Elevated Temperatures, Metall. Trans. A, 1975, 6, p 1991-1996

19. Y.-W. Kim, Intermetallic Alloys Based on Gamma Titanium Aluminide, JOM, 1989, 41, p 24-30

20. J.D. Sunderkötter, H.J. Schmutzler, V.A.C. Haanappel, R. Hofman, W. Glatz, and H. Clemens, The High-Temperature Oxidation Behaviour Compared with Ti-48Al-2Cr-0.2Si and Ti-48Al2Cr-2Nb Compared with Ti-48Al-2Cr, Intermetallics, 1997, 5(7), p 525-534

21. Y.W. Kim, Ordered Intermetallic Alloys, Part III: Gamma Titanium Aluminides, JOM, 1994, 46, p 30-39

22. F.H. Froes, C. Suryanarayana, and D. Eliezer, Synthesis, Properties and Applications of Titanium Aluminides, J. Mater. Sci., 1992, 27, p 5113-5140

23. M. Yamaguchi, High Temperature Intermetallics-With Particular Emphasis on TiAl, Mater. Sci. Technol., 1992, 8, p 299-307

24. D.M. Dimiduk, D.B. Miracle, and C.H. Ward, Development of Intermetallic Materials for Aerospace Systems, Mater. Sci. Technol., 1992, 8(4), p 367-375. https://doi.org/10.5402/2012/ 305692

25. M.P. Brady, W.J. Brindley, J.L. Smialek, and I.E. Locd, The Oxidation and Protection of Gamma Titanium Aluminides, $J$. Miner. Met. Mater. Soc., 1996, 48(11), p 46-50

26. B.G. Kim, G.M. Kim, and C.J. Kim, Oxidation Behavior of TiAl$\mathrm{X}(\mathrm{X}=\mathrm{Cr}, \mathrm{V}, \mathrm{Si}, \mathrm{Mo}$ or $\mathrm{Nb})$ Intermetallics at Elevated Temperature, Scr. Metall. Mater., 1995, 33(7), p 1117-1125

27. Y.C. Zhu, Y. Zhang, X.Y. Li, K. Fujita, and N. Iwamoto, The Effect of Niobium-Ion Implantation on the Oxidation Behavior of Gamma-TiAl Alloys in Static and Flowing Air, Oxid. Met., 2001, 55, p 119-135

28. T. Mori, S. Kuroda, H. Murakami, H. Katanoda, Y. Sakamoto, and S. Newman, Effects of Initial Oxidation on $\beta$ Phase Depletion and Oxidation of CoNiCrAlY Bond Coatings Fabricated by Warm Spray and HVOF Process, Surf. Coat. Technol., 2013, 221, p 59-69

29. P. Cao, B. Gabbitas, A. Salman, D.L. Zhang, and Z.H. Han, Consolidation of TiAl Powder by Thermal Spray Processes, $A d v$. Mater. Res., 2007, 29-30, p 159-162

30. J.K. Lee, M.H. Oh, H.K. Lee, and D.M. Wee, Plasma-Sprayed Al-21Ti-23Cr Coating for Oxidation Protection of TiAl Alloys, Surf. Coat. Technol., 2004, 182, p 363-369

31. D. Dewald, M. Austin, E. Laitila, and D. Mikkola, Cubic Titanium Trialuminide Thermal Spray Coatings-A Review, $J$. Therm. Spray Technol., 2001, 10, p 111-117

32. K.A. Khor, Y. Murakoshi, M. Takahashi, and T. Sano, Microstructure Changes in Plasma Sprayed TiAl Coatings after Hot Isostatic Pressing, J. Mater. Sci. Lett., 1996, 15, p 1801-1804

33. Y. Hoshiyama, H. Miyake, K. Murakami, and H. Nakajima, Composit Deposits Based on Titanium Aluminide Produced by Plasma Spraying, Mater. Sci. Eng. A, 2002, 333(1-2), p 92-97

34. A. Salman, B. Gabbitas, J. Li, and D. Zhang, Tribological Properties of Thermally Sprayed TiAl- $\mathrm{Al}_{2} \mathrm{O}_{3}$ Composite Coating, IOP Conf. Ser. Mater. Sci. Eng., 2009, 4(1), p 012006 
35. S. Knippscheer and G. Frommeyer, Intermetallic TiAl(Cr, Mo, Si) Alloys for Lightweight Engine Parts, Adv. Eng. Mater., 1999, 1(3-4), p 187-191

36. I. Agote, J. Coleto, M. Gutiérrez, A. Sargsyan, M. García de Cortazar, M.A. Lagos, I.P. Borovinskaya, A.E. Sytschev, V.L. Kvanin, N.T. Balikhina, S.G. Vadchenko, K. Lucas, A. Wisbey, and L. Pambaguian, Microstructure and Mechanical Properties of Gamma TiAl Based Alloys Produced by Combustion Synthesis + compaction Route, Intermetallics, 2008, 16, p 1310-1316. https:// doi.org/10.1016/j.intermet.2008.08.007

37. M. Gizynski, S. Miyazaki, J. Sienkiewicz, S. Kuroda, H. Araki, H. Murakami, Z. Pakiela, and A. Yumoto, Formation and Subsequent Phase Evolution of Metastable Ti-Al Alloy Coatings by Kinetic Spraying of Gas Atomized Powders, Surf. Coat. Technol., 2017, 315, p 240-249

38. H. Chandler, Heat Treater's Guide: Practices and Procedures for Nonferrous Alloys, ASM International, Materials Park, 2006

39. S. Kuroda, R.M. Molak, M. Watanabe, and H. Araki, Velocity Measurement of Sprayed Particles and Coatings Fabrication of Titanium Alloys by High-Pressure Warm Spray, Therm. Spray 2013 Proc. Int. Spray Conf., 2013, 6, p 263-265

40. S. Kuroda, J. Kawakita, M. Watanabe, and H. Katanoda, Warm Spraying-A Novel Coating Process Based on High-Velocity Impact of Solid Particles, Sci. Technol. Adv. Mater., 2008, 9(3), p 033002

41. S. Kuroda, M. Watanabe, K. Kim, and H. Katanoda, Current Status and Future Prospects of Warm Spray Technology, J. Therm. Spray Technol., 2011, 20, p 653-676

42. R.M. Molak, H. Araki, M. Watanabe, H. Katanoda, N. Ohno, and S. Kuroda, Warm Spray Forming of Ti-6Al-4V, J. Therm. Spray Technol., 2014, 23(1-2), p 197-206

43. G. Shao and P. Tsakiropoulos, Solidifcation Structures of Ti-AlCr Alloys, Intermetallics, 1998, 1999(7), p 579-587

44. W.Y. Li, H. Liao, C.J. Li, H.S. Bang, and C. Coddet, Numerical Simulation of Deformation Behavior of Al Particles Impacting on Al Substrate and Effect of Surface Oxide Films on Interfacial Bonding in Cold Spraying, Appl. Surf. Sci., 2007, 253, p 50845091

45. A. Huguet and A. Menand, Interstitial Solubility in Gamma and Alpha2 Phases of TiAl-Based Alloys, Acta Mater., 1996, 44(I), p 4729

46. S.A. Kekare and P.B. Aswatch, Oxidation of TiAl Based Intermetallics, J. Mater. Sci., 1997, 2, p 2485-2499

47. S. Becker, A. Rahmel, M. Schorr, and M. Schütze, Mechanism of Isothermal Oxidation of the Intel-Metallic TiAl and of TiAl Alloys, Oxid. Met., 1992, 38, p 425-464

48. R.G. Reddy, X. Wen, and M. Divakar, Isothermal Oxidation of TiAl Alloy, Metall. Mater. Trans. A, 2001, 32, p 2357-2361

49. G. Meier, F. Pettit, and S. Hu, Oxidation Behavior of Titanium Aluminides, J. Phys., 1993, 03(C9), p 395-402
50. L. Huang, P.K. Liaw, and C.T. Liu, Microstructures and Mechanical Properties of the TiAlNb Alloys, in Eighteenth Conf. Foss. Energy Mater., June 2-4, 2004, Oak Ridge, TN, 2008.

51. S. Becker, A. Rahmel, M. Schorr, and M. Schütze, Mechanism of Isothermal Oxidation of the Intel-Metallic TiAl and of TiAl Alloys, Oxid. Met., 1992, 38(5-6), p 425-464

52. C. Lang and M. Schutze, TEM Investigations of the Early Stages of TiAl Oxidation, Oxid. Met., 1996, 46(3-4), p 255-285

53. M. Brady, The Role of $\mathrm{Cr}$ in Promoting Protective Alumina Scale Formation by $\gamma$-Based Ti-Al-Cr Alloys-I. Compatibility with Alumina and Oxidation Behavior in Oxygen, Acta Mater., 1997, 45(6), p 2357-2369

54. M. Pfeiler, C. Scheu, H. Hutter, J. Schnöller, C. Michotte, C. Mitterer, and M. Kathrein, On the Effect of Ta on Improved Oxidation Resistance of Ti-Al-Ta-N Coatings, J. Vac. Sci. Technol. A Vac. Surf. Film, 2009, 27, p 554

55. C. Leyens and M. Peters, Titanium and Titanium Alloys, Fundamentals and Applications, Wiley, Hoboken, 2003

56. M. Jones, A. Horlock, P. Shipway, D. McCartney, and J. Wood, A Comparison of the Abrasive Wear Behaviour of $\mathrm{HVOF}$ Sprayed Titanium Carbide- and Titanium Boride-Based Cermet Coatings, Wear, 2001, 251(1-12), p 1009-1016. https://doi.org/ 10.1016/s0043-1648(01)00702-5

57. C.E. Lowell, C.A. Barrett, R.W. Palmer, J.V. Auping, and H.B. Probst, COSP: A Computer Model of Cyclic Oxidation, Oxid. Met., 1991, 36(1-2), p 81-112

58. H. Choi, B. Yoon, H. Kim, and C. Lee, Isothermal Oxidation of Air Plasma Spray NiCrAlY Bond Coatings, Surf. Coat. Technol., 2002, 150(2-3), p 297-308

59. Z.G. Zhang, P.Y. Hou, F. Gesmundo, and Y. Niu, Effect of Surface Roughness on the Development of Protective $\mathrm{Al}_{2} \mathrm{O}_{3}$ on Fe-10Al (at.\%) Alloys Containing 0-10 at.\% Cr, Appl. Surf. Sci. Elsevier BV, 2006, 253(2), p 881-888

60. F.H. Stott, G.C. Wood, and M.G. Hobbyt, A Comparison of the Oxidation Behavior of Fe-Cr-AI, Ni-Cr-AI, and Co-Cr-Al Alloys, Oxid. Met., 1971, 3(2), p 103-113

61. J.L. Evans, Effect of Surface Roughness on the Oxidation Behavior of the Ni-Base Superalloy ME3, J. Mater. Eng. Perform., 2010, 19(October), p 1001-1004. https://doi.org/10.1007/ s11665-010-9605-5

62. L.Y. Ni, Z.L. Wu, and C.G. Zhou, Effects of Surface Modification on Isothermal Oxidation Behavior of HVOF-Sprayed NiCrALY Coatings, Prog. Natl. Sci. Mater. Int. Chin. Mater. Res. Soc., 2011, 21(2), p 173-179

Publisher's Note Springer Nature remains neutral with regard to jurisdictional claims in published maps and institutional affiliations. 